\title{
Transcriptome analysis of air-breathing land slug, Incilaria fruhstorferi reveals functional insights into growth, immunity, and reproduction
}

Bharat Bhusan Patnaik ${ }^{2 \dagger}$, Jong Min Chung ${ }^{1 \dagger}$, Hee Ju Hwang ${ }^{1}$, Min Kyu Sang ${ }^{1}$, Jie Eun Park ${ }^{1}$, Hye Rin Min ${ }^{1}$, Hang Chul Cho', Neha Dewangan², Snigdha Baliarsingh², Se Won Kang ${ }^{3}$, So Young Park ${ }^{4}$, Yong Hun Jo ${ }^{5}$, Hong Seog Park ${ }^{6}$, Wan Jong Kim ${ }^{1}$, Yeon Soo Han ${ }^{5}$, Jun Sang Lee ${ }^{7}$ and Yong Seok Lee ${ }^{1^{*}}$

\begin{abstract}
Background: Incilaria (= Meghimatium) fruhstorferi is an air-breathing land slug found in restricted habitats of Japan, Taiwan and selected provinces of South Korea (Jeju, Chuncheon, Busan, and Deokjeokdo). The species is on a decline due to depletion of forest cover, predation by natural enemies, and collection. To facilitate the conservation of the species, it is important to decide on a number of traits related to growth, immunity and reproduction addressing fitness advantage of the species.

Results: The visceral mass transcriptome of I. fruhstorferi was enabled using the Illumina HiSeq 4000 sequencing platform. According to BUSCO (Benchmarking Universal Single-Copy Orthologs) method, the transcriptome was considered complete with 91.8\% of ortholog genes present (Single: 70.7\%; Duplicated: 21.1\%). A total of 96.79\% of the raw read sequences were processed as clean reads. TransDecoder identified 197,271 contigs that contained candidate-coding regions. Of a total of 50,230 unigenes, 34,470 (68.62\% of the total unigenes) annotated to homologous proteins in the Protostome database (PANM-DB). The GO term and KEGG pathway analysis indicated genes involved in metabolism, phosphatidylinositol signalling system, aminobenzoate degradation, and T-cell receptor signalling pathway. Many genes associated with molluscan innate immunity were categorized under pathogen recognition receptor, TLR signalling pathway, MyD88 dependent pathway, endogenous ligands, immune effectors, antimicrobial peptides, apoptosis, and adaptation-related. The reproduction-associated unigenes showed homology to protein fem-1, spermatogenesis-associated protein, sperm associated antigen, and testis expressed sequences, among others. In addition, we identified key growth-related genes categorized under somatotrophic axis, muscle growth, chitinases and collagens. A total of 4822 Simple Sequence Repeats (SSRs) were also identified from the unigene sequences of I. fruhstorferi.
\end{abstract}

(Continued on next page)

\footnotetext{
* Correspondence: yslee@sch.ac.kr

${ }^{\dagger}$ Bharat Bhusan Patnaik and Jong Min Chung are first author(s).

'Department of Life Science and Biotechnology, College of Natural Sciences,

Soonchunhyang University, 22 Soonchunhyangro, Shinchang-myeon, Asan,

Chungchungnam-do 31538, South Korea

Full list of author information is available at the end of the article
}

(c) The Author(s). 2019 Open Access This article is distributed under the terms of the Creative Commons Attribution 4.0 International License (http://creativecommons.org/licenses/by/4.0/), which permits unrestricted use, distribution, and reproduction in any medium, provided you give appropriate credit to the original author(s) and the source, provide a link to the Creative Commons license, and indicate if changes were made. The Creative Commons Public Domain Dedication waiver (http://creativecommons.org/publicdomain/zero/1.0/) applies to the data made available in this article, unless otherwise stated. 


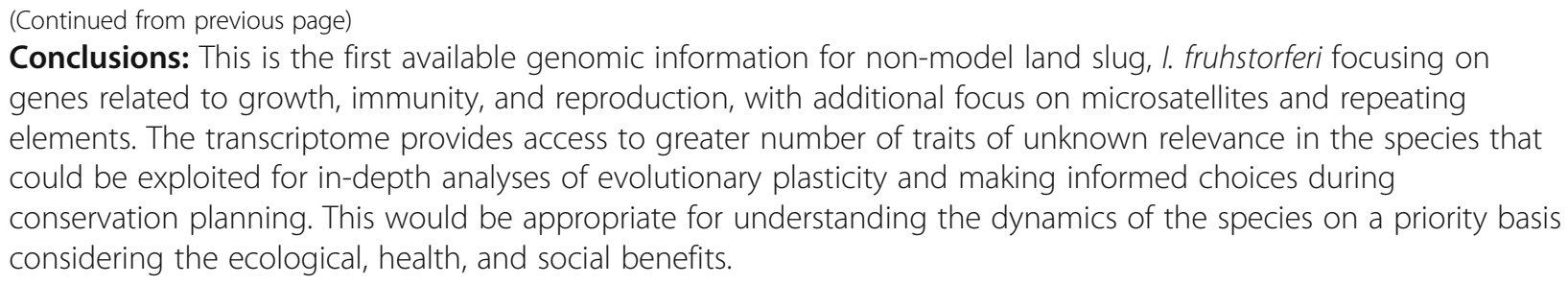

Keywords: Incilaria fruhstorferi, Transciptome, de novo analysis, Immunity, Sex-linked genes, Simple sequence repeats, Tollip, Peptidoglycan recognition protein

\section{Background}

Gastropod slugs are known to inhabit dynamic ecosystems with spectacular local abundances. Most of the slug species were able to expand their habitat requirements over in mountains. But, lately the distributional range of the species has spread to lowlands due to crop irrigation and watering of gardens. Incilaria fruhstorferi (NCBI txid 414,506; syn. Meghimatium fruhstorferi or Philomycus fruhstorferi Collinge, 1901) is a medium to large air-breathing slug belonging to superfamily Arionidae and family Philomycidae [1]. The members of this family including the Incilaria species show restricted distribution. I. fruhstorferi species has been recorded from Japan, Taiwan, and South Korea (Chuncheon, Busan, Deokjeokdo provinces and Jeju Island) [2].

Considering the local distributions of Incilaria species and for its sustainable protection in the wild, it is imperative to implement informed conservation planning practices. This would help to understand habitat-level requirements as well as the potential of acclimatization and adaptation of the species to changing environmental conditions. In this regard, the genomic information of the species would help to screen the relevant phenotypes influencing the distributional range of the species. Currently, the only available genomic information for $I$. fruhstorferi in the National Canter for Biotechnology Information (NCBI) is the cytochrome oxidase subunit I (COI) gene and the C-type lectins viz. Incilarin A, B and C [3]. Although Incilarin could play a putative role in host defense through the recognition of molecular patterns in microbial cell surfaces, a detailed functional characterization is lacking. Further, the lack of genomic information is an impediment towards understanding the ecological adaptation strategies of Incilaria sp. in the wild with reference to growth, immunity, and reproduction. Hence, cataloguing the genomic resources would guide successful establishment of the species in the wild.

The advent of effective and cost-efficient next-generation sequencing approaches have led to an increased information on non-model species at the genomic and transcriptomic levels. Conservation biologists and ecologists have found appropriate applications and an added incentive for protecting declining biodiversity in the wake of global climate change. Transcriptomics approaches have identified the regulatory genes with major impacts on development, immunity, and reproduction in many molluscan species including Aplysia californica [4], Crassostrea virginica [5], Biomphalaria glabrata [6], Radix auricularia [7], and the Manila clam, Ruditapes philippinarum [8]. Further, completed mitochondrial genomes of gastropods, bivalves, and cephalopods have been used to understand the phylogeny of the taxon $[9,10]$. By and large, the transcriptome projects involving molluscs have included commercially exploited species and/or endangered species. This includes the critically endangered land snail, Satsuma myomphala [11]; Korea endangered freshwater pearl bivalve, Cristaria plicata [12], Australian mollusc, Dicathais orbita [13], Sydney rock oyster, Saccostrea glomerata [14], and the freshwater snail, Oncomelania hupensis [15], among others. The above studies identified genes with major impacts on ecologically relevant traits. Furthermore, transcriptome analysis has been useful in large-scale screening of microsatellites such as the simple sequence repeats (SSRs) and single nucleotide polymorphisms (SNPs). In the case of molluscan species, these microsatellites would be valuable in genetic improvement of stocks through marker-assisted breeding and understanding the diversity of the species within and among populations [16, 17]. In our earlier studies, we have taken the lead in cataloguing the genomic resources for Korean endemic land snails, Aegista chejuensis and Aegista quelpartensis [18], and the threatened snail, Ellobium chinense [19] as part of prioritized conservation efforts in South Korea.

In the present study, the Illumina HiSeq 4000 platform was used to acquire and annotate the transcriptome of air-breathing land slug, Incilaria fruhstorferi. This is to investigate the ecological dynamics of the species through screening of growth, immunity, and reproduction related genes. We conducted a de novo assembly of the transcriptome, screened the ORF containing transcripts, and annotated the same to homologous sequences in nucleotide and protein databases including the locally curated Protostome database (PANM-DB) [20]. We screened repeats predominant in the transcriptome and identified potential 
SSR markers for effective use in population genetic studies. Furthermore, we investigated genes related to growth, reproduction, and immune function with special reference to the pathogen recognition receptor PGRP-SC2 and Toll-interacting protein, also known as Tollip, using phylogenetic analysis. Hence, by utilizing paired-end (PE) Illumina transcriptome sequencing, we provide the first set of genomic information in the non-model land slug I. fruhstorferi. Further, with the screening of adaptation related genes, we investigate the plasticity of the species to sustain in varied climatic zones through compatibility in terms of biological, ecological, and physiological responses. Further, we have screened candidate genes involved in Toll signalling pathway, apoptotic pathway, and inflammatory response pathways. We assume that the transcriptome resources would provide unbiased access to phenotypic screens of many traits in the species. This would promote beneficial hybridization as a means of conservation planning.

\section{Methods}

\section{Sample collection}

Specimens of I. fruhstorferi were collected during July 2015, from a location close to Sammak-gil, Cheong-pyeong-ri, Buksan-myeon, Chuncheon-si, Gangwon-do province, Republic of Korea. A total of 3 specimens ranging from 5 to $7 \mathrm{~g}$ were collected. The air-breathing slug, I. fruhstorferi is shown in Fig. 1a. After transferring the specimens to the laboratory, the visceral mass tissue (containing all the organs of the digestive and reproductive system) were dissected and immediately placed into liquid nitrogen until RNA preparation. The study follows ethical principles of use of experimental animals in biomedical research [21].

\section{RNA extraction and Illumina sequencing}

Total RNA was extracted from the visceral mass tissue using the TRIzol reagent according to manufacturer's instructions, and treated with RNase-free DNaseI. The extracted RNA was checked for concentration, purity and integrity using NanoDrop-2000 spectrophotometer and 2100 Bioanalyzer. In this case, the concentration of RNA was $3.15 \mathrm{ng} / \mu \mathrm{l}$ in a volume of $18 \mu \mathrm{l}=56.7 \mathrm{ng} / \mu \mathrm{l}$ and was considered as RNA input for library preparation and downstream processing. mRNA-seq sample preparation kit (Illumina, CA, USA) was used to construct an mRNA-seq library following the manufacturer's instructions. Briefly, mRNA was purified from total RNA using oligodT magnetic beads. The mRNA was broken into short fragments of $200 \mathrm{nt}$ using an RNA fragmentation kit (Ambion, TX, USA). The short mRNA fragments were reverse-transcribed into first strand cDNA using random primers and reverse transcriptase and second strand cDNA with RNase $\mathrm{H}$ and DNA polymerase $\mathrm{I}$. After purification using QIAquick PCR extraction kit, the cDNA was ligated to sequencing adapters with paired-end (PE) Adapter Oligo Mix using T4 DNA ligase. DNA fragments of the desired size $(200 \pm 25 \mathrm{bp})$ were sequenced on the Illumina HiSeq 4000 sequencing platform to generate $125 \mathrm{bp}$ PE reads. All the raw data obtained from sequencing were registered with NCBI Sequence Read Archive (SRA) under SRR5936593, BioProjectPRJNA398441, and BioSample-SAMN07510659.

\section{Processing of sequencing data and de novo assembly}

Before the processing of clean reads for downstream assembly and annotation analysis, the raw sequencing reads were cleaned for low-quality sequences (Cutadapt 1.18 with default parameters), such as the adapter sequences and repeated reads [22]. The quality of the raw reads in fastq format was assessed using FastQC software version 0.11 .5 (http://www.bioinformatics.babraham.ac.uk). The clean reads, thus obtained were carried forward for transcriptome de novo assembly using the Trinity short read program under the default settings of a minimum allowed length of $200 \mathrm{bp}$. Under this program, the Illumina shortreads are clustered together to form the contigs ('Inchworm' assembly step), contigs clustered and processed to de Bruijin graph ('Chrysalis'), and extraction of all probable sequences from individual components de Bruijin graphs that are parallelized ('Butterfly'). Redundancy from the clustered datasets was removed using cd-hit-est version 4.6.6 [23], with TransDecoder release version 2.0.3 (https://github.com/TransDecoder/ TransDecoder/wiki) as a protein-prediction tool. BUSCO version 3.0.1 [24] using the metazoan_odb9 [25] was used to create a lineage dataset and assess the completeness of the transcriptome.

\section{Homology search and functional annotation}

The non-redundant unigenes were annotated to the locally curated comprehensive protein database called PANM reference database (PANM-DB) using BLASTx. The database version 2.0 release contained a total of 7,571,246 protein sequences covering the Protostomes (Arthropoda, Mollusca, and Nematoda) [26]. BLASTx searches with an E-value threshold of 1.0E-5 were also used to identify homologous sequences in the Swiss-Prot protein sequence and UniGene nucleotide sequence databases. The EuKaryotic Orthologous Groups (KOG)-DB was also scanned for understanding the categorization of unigenes to specific functional descriptors such as 'Cellular Processes and Signalling', 'Information Storage and Processing,' 'Metabolism', and 'Poorly characterized' (https://www.ncbi.nlm.nih.gov/COG/). The InterProScan feature of BLAST2GO professional suite (https://www.blast2go.com) was utilized to annotate the conserved domains in the unigenes. Further, the Gene Ontology (GO) annotations were retrieved with an 


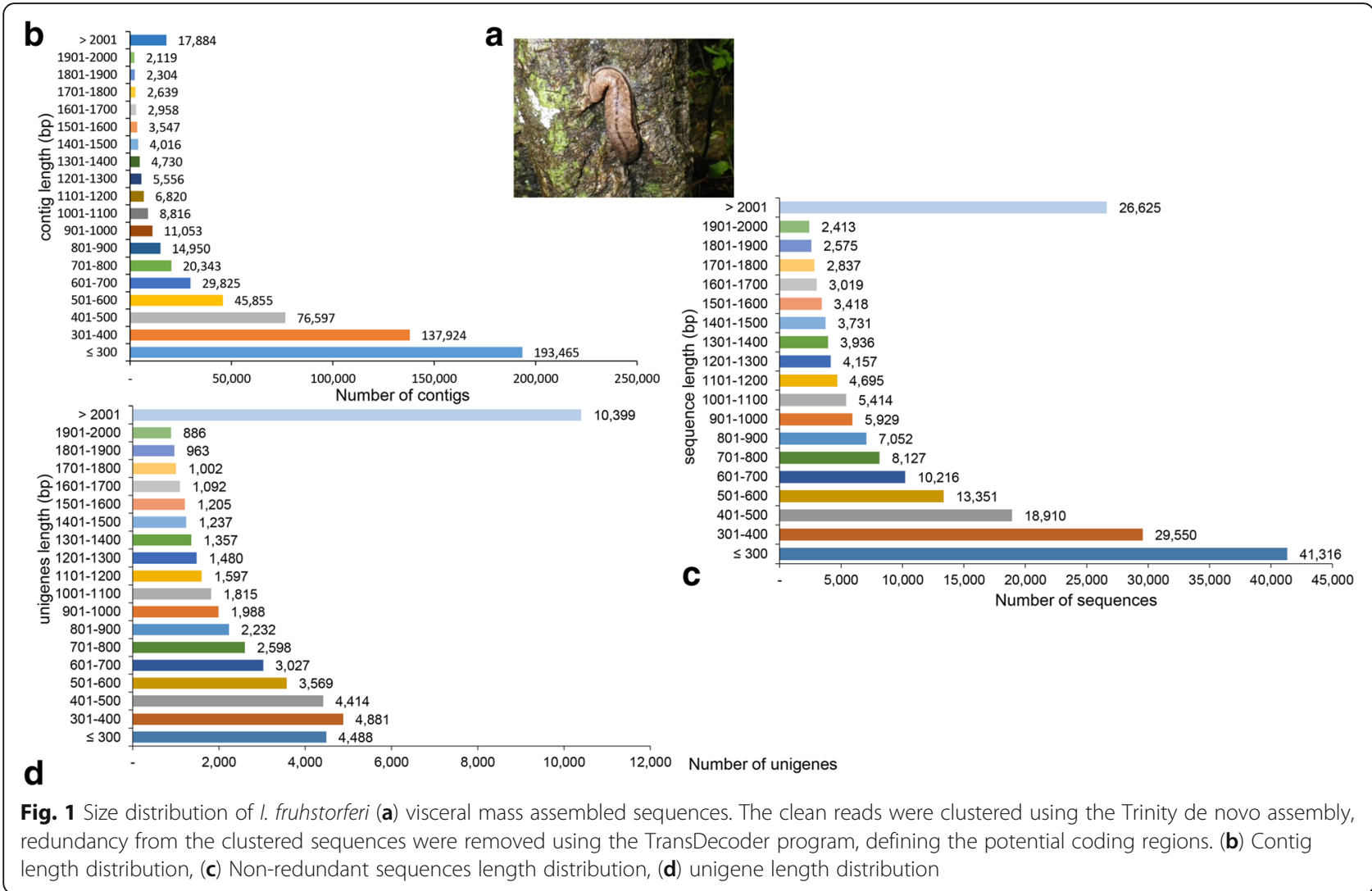

E-value threshold of 1.0E-5 and classified into three categories at level 2 (biological process, cellular component, and molecular function). The GO functional classification of the unigenes was finally plotted using Web Gene Ontology Annotation Plot version 2.0 (WEGOv2.0) software [27]. Pathway analysis of unigene sequences were analyzed using the Kyoto Encyclopaedia of Genes and Genomes (KEGG) database release 84.0 (http://www.genome.jp/tools/kaas/).

\section{Gene discovery related to immunity, reproduction, and growth}

A keyword search was employed to identify the candidate genes (involved in I. fruhstorferi immunity, reproduction, and growth) from the BLASTx annotated PANM-DB. Keywords included representative names of genes involved in different stages of molluscan immunity, cell signalling process, sex-determination, reproduction, and growth. Further, the GO terms and KEGG classification information was also utilized to identify the putative function of the gene products of the transcripts (the translated proteins). A comprehensive network of immunity-related transcripts was categorized under 'Pathogen Recognition Receptor', 'TLR Signalling Pathway (Adapter proteins, MyD88-dependent pathway)', 'Endogenous Ligands',
'Immune Effectors', 'Antimicrobial Peptides', 'Cytokines and Cytokine Receptors', and 'Apoptosis'.

For evaluating the assembly and annotation obtained for I. fruhstorferi, we performed PCR-sequencing based approach. Total RNA was extracted from I. fruhstorferi whole- body using the Trizol method. cDNA was synthesized using AccuPower RT PreMix (Bioneer, Korea) with Oligo $(\mathrm{dT})_{12-18}$ primer on a MyGenie 96 thermal cycler (Bioneer, Korea). To screen the transcriptome-derived unigenes for Tollip and PGRP-SC2, we generated a database using the FASTA file derived from NCBI with the keyword "gastropoda + gene name". Subsequently, we used the database for local-BLAST to find the unigene which has the target gene. The screened Tollip and PGRP-SC2 sequences were used as the subject sequence for primer designing using Primer3 ver 4.0 (http://bioinfo. ut.ee/primer3-0.4.0/). The primers for PCR validation are as follows: Fwd-5'-ACTTTCTGCGTGCTGGATCT-3' and Rev- 5'-TTCCTACACGCACTCGACAG-3' (Tollip); Fwd-5'-CCAGTATTTTTGACACCAAGTTCA-3' and Rev-5'-GGCCAGGTTCTTATCTCTTGG-3' (PGRP-SC2). $\beta$-actin gene was considered as an endogenous control (Fwd-5'-GTGCCAGACGCCTAACAGTA-3' and Rev5'-GATGTCACGAACAATCTCACG-3'). PCR (35 cycles) was conducted using PowTaq polymerase (GnC company, Daejeon, Korea) at an annealing temperature of $54^{\circ} \mathrm{C}$. 


\section{Bioinformatics analysis}

The I. fruhstorferi unigenes showing homology to Tollip and PGRP-SC2 sequences in PANM DB were subjected to FGENESH gene-finding software using the online Softberry suite [28]. The ORF sequences confirmed using the online tool ORFPredictor [29] were used as queries against the NCBInr database to find the homologous sequences. Once validated, the translated amino acid sequences were used as query for the predictive analysis of protein sequence and structure. The physicochemical properties of the protein sequences were analysed using DNASTAR LASERGENE ver.7.1 Protean tool (http://www.dnastar.com/). SignalP at http:// www.cbs.dtu.dk/services/SignalP/ was used to examine the presence of signal peptide. Transmembrane regions were predicted using the TMHMM Server v.2.0 (http:// www.cbs.dtu.dk/services/TMHMM/). The domain architecture of the protein sequences were retrieved using the SMART domain analysis program at http://smart.emblheidelberg.de/. The secondary structure was predicted using PSIPRED program at http://bioinf.cs.ucl.ac.uk/psipred_new/. All the pairwise and multiple sequence alignments were performed using ClustalX2 program [30]. The alignment files (. aln extension) generated were analyzed in GeneDoc sequence visualization software for Windows [31]. The phylogenetic tree was constructed using the maximum-likelihood method with the bootstrap trials set to 1000 . The phylogenetic tree was visualized using the Molecular Evolutionary Genetics Analysis (MEGA) ver7.0 suite at https://www.megasoftware.net/.

\section{Repeats and microsatellite marker discovery}

The Perl script program MicroSAtellite (MISA) (http:// pgrc.ipk-gatersleben.de/misa/) was used to detect Simple Sequence Repeats (SSRs) as di-, tri-, tetra-, penta-, and hexanucleotide repeats from unigene sequences $>2 \mathrm{~Kb}$. The homology-based repeat search program, RepeatMasker (version 4.0.6) was used to screen representative repeats such as the 'Short Interspersed Nuclear Elements (SINEs)', 'Long Interspersed Nuclear Elements (LINEs)', 'Long Terminal Repeat (LTR) elements', and 'DNA elements' https://www.girinst.org/ (http://ftp.genome.washington.edu/ RM/RepeatMasker.html).

\section{Results}

Sequencing reads, quality control, and de novo assembly A mRNA-Seq library was constructed after isolation of Total RNA from the visceral mass tissue of Incilaria fruhstorferi. The total number of raw reads achieved for $I$. fruhstorferi transcriptome was $121,442,128$. The pre-processing pipeline of raw reads included the trimming of the adapter sequences from the read pairs using the Cutadapt program, filtering low-quality reads (> $50 \%$ of bases having Q-value $\leq 20$ ), and ambiguous bases (Additional file 1: Table S1).
On an average, $0.6 \%$ of reads were discarded and length of reads after trimming was $300.2 \mathrm{bp}$. A total of $117,541,612$ high-quality sequencing reads $(16,896,672,304$ bases) that constitutes $96.79 \%$ sequences $(92.14 \%$ bases) were obtained from the transcriptome quality control. De novo assembly of the clean sequence reads was conducted using the Trinity assembly, generating 591,401 contigs with the largest contig size of $15,717 \mathrm{bp}$. About $31.12 \%$ of the contigs were considered $\geq 500 \mathrm{bp}$ in length, with an overall mean length of $559.3 \mathrm{bp}$. Out of the total of 591,401 contig sequences, 197,271 sequences with potential ORF were screened including 107,658 sequences of lengths $\geq 500 \mathrm{bp}$. TGICL (TIGR gene indices clustering tool) clustering of the assembled sequences with potential open reading frames (ORF) identified 50,230 unigene sequences $(67,667,335$ bases), with the smallest to largest unigenes ranging from $135 \mathrm{bp}$ to $26,139 \mathrm{bp}$. A statistical summary of Trinity assembly, TransDecoder utility, and the de novo assembled unigenes is depicted in Table 1. Further, the unigenes showed a greater length distribution when compared with the contigs and the assembled sequences. Almost $32.71 \%$ of contigs were $\leq 300$ bp and only $3.02 \%$ was above $2001 \mathrm{bp}$ (Fig. 1b). This is in contrast to $20.94 \%$ ( $\leq 300 \mathrm{bp}$ ) and $13.5 \%$ (> $2000 \mathrm{bp}$ ) in the ORF containing transcripts obtained by TransDecoder program (Fig. 1c). Almost $20.7 \%$ unigenes showed lengths of $>2000 \mathrm{bp}$, increasing the possibility of obtaining full-length transcripts (Fig. 1d). Based on BUSCO, we assessed the "completeness" of the $I$. fruhstorferi transcriptome. A total of 978 number BUSCOs were searched, out of which 691 (91.8\%) were complete and single-copy BUSCOs, 206 complete and duplicated BUSCOs (21.1\%), 50 (5.1\%) fragmented, and 31 (3.1\%) missing BUSCOs.

\section{Sequence annotation of unigenes for homologous matches}

Of the 50,230 unigenes, 34,470 (68.62\%) sequences showed matches to homologous sequences in PANM-DB at an E-value cut-off of 1.0E-5, followed by 16,629 (33.11\%) in Swiss-Prot, and 6624 (13.19\%) in NCBI's UniGene database. Annotation statistics of $I$. fruhstorferi unigenes against the public protein and nucleotide databases is represented in Table 2. In total, 35,204 unigenes (70.09\%) showed matches to homologous sequences in the databases. Out of the annotated sequences, 20,174 sequences (57.31\%) showed lengths of $\geq 1000 \mathrm{bp}$. Most of the unigenes $(34,470)$ showed homologous matches to PANM-DB. Further, 15,760 sequences (31.38\%) showed no homologous matches to the database. Possibly, most of the non-annotated sequences are shorter with lesser likelihood of conserved domains and motifs. Further, the non-annotation can be ascribed to orphaned untranslated regions (UTRs), sequences from uncharacterized genes, or sequences unique to $I$. fruhstorferi. The Venn diagram illustrated in Fig. 2 reveals that 
Table 1 Statistical summary of Incilaria fruhstorferi transcriptome

\begin{tabular}{|c|c|}
\hline \multicolumn{2}{|l|}{ Total number of raw reads } \\
\hline -Number of sequences & $121,442,128$ \\
\hline -Number of bases & $18,337,761,328$ \\
\hline \multicolumn{2}{|l|}{ Total number of clean reads } \\
\hline -Number of sequences & $117,541,612$ \\
\hline -Number of bases & $16,896,672,304$ \\
\hline -Mean length of contig (bp) & 143.8 \\
\hline -N50 length of contig (bp) & 151 \\
\hline -GC \% of contig & 40.87 \\
\hline High-quality reads (\%) & 96.79 (sequences), 92.14 (bases) \\
\hline \multicolumn{2}{|l|}{ Contig information } \\
\hline -Total number of contig & 591,401 \\
\hline -Number of bases & $330,746,158$ \\
\hline -Mean length of contig (bp) & 559.3 \\
\hline -N50 length of contig (bp) & 637 \\
\hline -GC \% of contig & 38.04 \\
\hline -Largest contig (bp) & 15,717 \\
\hline -No. of large contigs ( $\geq 500 \mathrm{bp}$ ) & 184,017 \\
\hline \multicolumn{2}{|l|}{ After TransDecoder } \\
\hline -Total number of sequence & 197,271 \\
\hline -Number of bases & $202,308,633$ \\
\hline -Mean length of sequence (bp) & 1025.5 \\
\hline -N50 length of sequence (bp) & 1757 \\
\hline -GC \% of sequence & 39.87 \\
\hline -Largest sequence (bp) & 15,717 \\
\hline -No. of large sequence ( $\geq 500 \mathrm{bp})$ & 107,658 \\
\hline \multicolumn{2}{|l|}{ Unigene information } \\
\hline -Total number of unigenes & 50,230 \\
\hline -Number of bases & $67,667,335$ \\
\hline -Mean length of unigene (bp) & 1347.1 \\
\hline -N50 length of unigene (bp) & 2069 \\
\hline -GC \% of unigene & 39.72 \\
\hline -Length ranges (bp) & $135-26,139$ \\
\hline
\end{tabular}

9457 sequences (27.44\%) out of the 34,470 show specific annotation to the homologous proteins in PANM-DB. A total of $13,789(40 \%)$ sequences, those that annotated to homologous sequences in PANM-DB also found hits in SwissProt and KOG DB, and 8195 sequences (23.77\%) annotated to all the four databases. A greater number of sequence annotation hits including the unique hits were represented under PANM-DB.
Table 2 Annotation of I. fruhstorferi unigene sequences against public protein and nucleotide databases. The unigenes are classified based on their sizes

\begin{tabular}{lllll}
\hline Databases & All transcripts & $\leq 300 \mathrm{bp}$ & $300-1000 \mathrm{bp}$ & $\geq 1000 \mathrm{bp}$ \\
\hline PANM-DB & 34,470 & 2118 & 12,429 & 19,923 \\
UNIGENE & 9105 & 281 & 2200 & 6624 \\
SwissProt & 23,840 & 611 & 6600 & 16,629 \\
KOG & 22,984 & 616 & 6382 & 15,986 \\
GO & 15,660 & 382 & 3721 & 11,557 \\
KEGG & 81 & - & 13 & 68 \\
IPS & 18,238 & 481 & 4711 & 13,046 \\
ALL & 35,204 & 2186 & 12,844 & 20,174 \\
\hline
\end{tabular}

\section{Homology characteristics and functional annotation of unigenes}

BLASTx analysis was performed using 34,470 unigenes against PANM-DB to characterize the homology matrices (Additional file 2: Figure S1). The E-value distribution reveals that $44.59 \%$ of the sequences show homology at $1.0 \mathrm{E}-50$ to $1.0 \mathrm{E}-5$ (Additional file 2: Figure S1A). Majority of unigenes $(37.15 \%)$ show an identity of $40-60 \%$, while only 41 sequences $(0.12 \%)$ show $100 \%$ identity to homologous sequences in PANM-DB (Additional file 2: Figure S1B). The highest number of unigenes (14,710 sequences; $42.67 \%)$ showed similarities in the range $60-80 \%$, while only 111 sequences $(0.32 \%)$ showed $100 \%$ similarity with the database sequences (Additional file 2: Figure S1C). The number of annotation hits as compared to no-hits increased in direct proportion to the length of unigenes (Additional file 2: Figure S1D). Sequences of lengths > 2001 bp showed the highest 9867 hits. It is obvious that with longer sequences the annotation improves

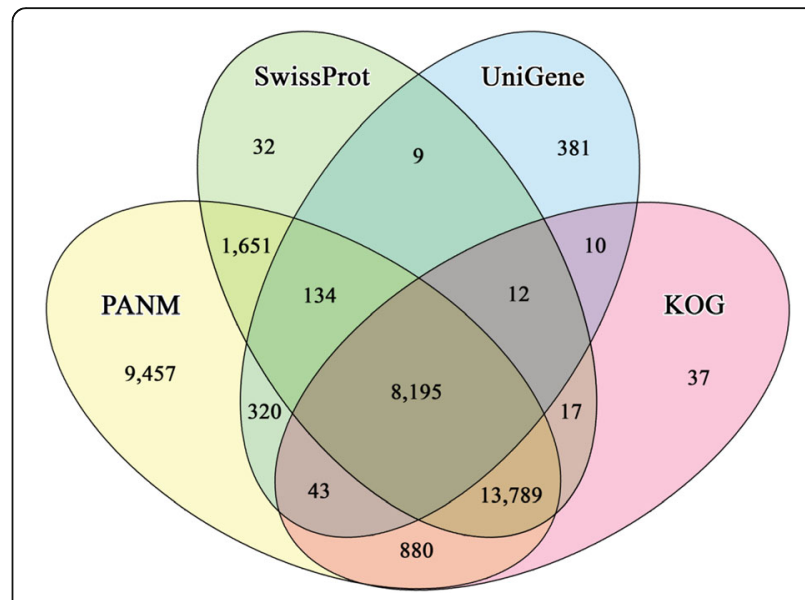

Fig. 2 Annotation of I. fruhstorferi unigenes against the public protein and nucleotide databases. Venn diagram showing homologous matches of unigenes to PANM DB, UniGene, SwissProt, and KOGDB (either specific or overlapping) 
because they are attributed with conserved protein domains representative of protein function. Further, considering the top-hit species distribution, 44.16 and $30.58 \%$ of the unigenes matched Aplysia californica and Biomphalaria glabrata, respectively (Additional file 3: Figure S2).

Of the 50,230 unigenes, 18,238 showed classic and conserved InterPro domains. A total of 1271 unigenes showed the predominant Zinc finger ( $\mathrm{Znf}), \mathrm{C} 2 \mathrm{H} 2$-type domain, followed by 985 and 703 sequences showing the P-loop containing nucleoside triphosphate hydrolase and Zinc finger RING/FYVE/PHD-type domains, respectively (Table 3 ). Other protein domains predominantly noticed in $I$. fruhstorferi unigene sequences include Protein kinase-like, Immunoglobulin-like fold, EGF-like, Galactose-binding, and Leucine-rich repeats. Further, to explore the functional direction of $I$. fruhstorferi unigenes, we annotated the sequences against the KOG, GO, and KEGG databases. A total of 22,984 sequences were annotated in the KOG database, out of which $69.55 \%$ of sequences had lengths of $\geq 1000 \mathrm{bp}$. Further, the sequences were classified under 25 KOG functional categories (Fig. 3). In the present annotation, 20.38\% of unigenes were classified under $\mathrm{R}$ term (General function prediction only), followed by 10.26 and $7.51 \%$ under $\mathrm{T}$ (Signal transduction mechanisms) and $\mathrm{S}$ (function

Table 3 List of top-20 protein domains found in I. fruhstorferi unigene sequences

\begin{tabular}{lll}
\hline Domain & Description & Unigene (Nos.) \\
\hline IPR013087 & Zinc finger C2H2-type & 1271 \\
IPR027417 & $\begin{array}{l}\text { P-loop containing nucleoside } \\
\text { triphosphate hydrolase }\end{array}$ & 985 \\
IPR013083 & Zinc finger, RING/FYVE/PHD-type & 703 \\
IPR012337 & Ribonuclease H-like domain & 664 \\
IPR000477 & Reverse transcriptase domain & 517 \\
IPR011009 & Protein kinase-like domain & 478 \\
IPR013783 & Immunoglobulin-like fold & 451 \\
IPR000742 & EGF-like domain & 445 \\
IPR000719 & Protein kinase domain & 416 \\
IPR015943 & WD40/YTN repeat-like-containing & 401 \\
& domain & 381 \\
IPR002156 & Ribonuclease H domain & 372 \\
IPR011989 & Armadillo-like helical & 368 \\
IPR017986 & WD40-repeat-containing domain & 367 \\
IPR016024 & Armadillo-type fold & 343 \\
IPR016040 & NAD(P)-binding domain & 337 \\
IPR008979 & Galactose-binding domain-like & 323 \\
IPR000504 & RNA recognition motif domain & 313 \\
IPR011990 & Tetratricopeptide-like helical domain \\
IPR032675 & Leucine-rich repeat domain, L domain-like & 303 \\
IPR020683 & Ankyrin repeat-containing domain & 293 \\
\hline
\end{tabular}

unknown) terms, respectively. A high proportion (20.01\%) of sequences also classified to the 'multi' category (sequences belonging to more than one functional term). The least populated KOG terms included H (co-enzyme transport and metabolism), Y (nuclear structure), and $\mathrm{N}$ (cell motility) with 141, 137, and 39 unigene sequences, respectively.

For high-quality functional analysis of genomic datasets, we used the bioinformatics platform Blast2GO v5.1 (https://www.blast2go.com/). GO-based annotation and KEGG pathway maps for the I. fruhstorferi genomic datasets were elucidated using the Blast2GO software platform. A total of 15,660 unigenes were annotated to GO functional categories such as 'Molecular function', 'Biological process', and 'Cellular component' (Additional file 4: Figure S3). The maximum $32.63 \%$ of the sequences were classified under 'Molecular function' category followed by only 4.27 and $3.21 \%$ sequences classified under 'Biological process' and 'Cellular component' category, respectively. Further, 26.79\% of sequences were classified to both 'Biological Process' and 'Molecular function' categories. A total of 2790 sequences (17.82\%) were classified under all the three GO functional categories (Additional file 4: Figure S3A). Only $38.55 \%$ of sequences annotated against $\mathrm{GO}$ database were categorized under a single $\mathrm{GO}$ term (Additional file 4: Figure S3B). Rest of the sequences participated under more than one GO term. The GO terms (at level 2) for each of the three categories are shown in Fig. 4. Within the 'Molecular function' category, the unigenes predominantly were predicted under binding (GO: 0005488), followed by catalytic activity (GO: 0003824) and transporter activity (GO: 0005215) (Fig. 4A). In the 'Cellular component' category, the top-represented GO terms included membrane (GO: 0016020), cell (GO: 0005623), and cell part (GO: 0044464) (Fig. 4B). Under 'Metabolic process' category, the most prominent GO terms included cellular process (GO: 0009987), metabolic process (GO: 0008152), and single-organism process (GO: 0044699) (Fig. 4C). We further annotated the assembled genomic sequences of $I$. fruhstorferi to associated biological pathways using the KEGG database. Only 81 sequences of enzymes were classified under 'Environmental Information Processing', 'Metabolism', and 'Organismal Systems' categories. These sequences are related to the 46 putative enzymes in the pathway (Table 4).

\section{Characterization of repeating elements and microsatellites in I. fruhstorferi transcriptome}

Repeating elements promiscuous in the unigene sequences of $I$. fruhstorferi were analyzed using the Repeatmasker program (Homo sapiens as the species parameter) under the RepBase database (http://www.girinst.org). As suggested in Table 5, the prominent repeating elements found were the LINEs, DNA repeating elements such as 


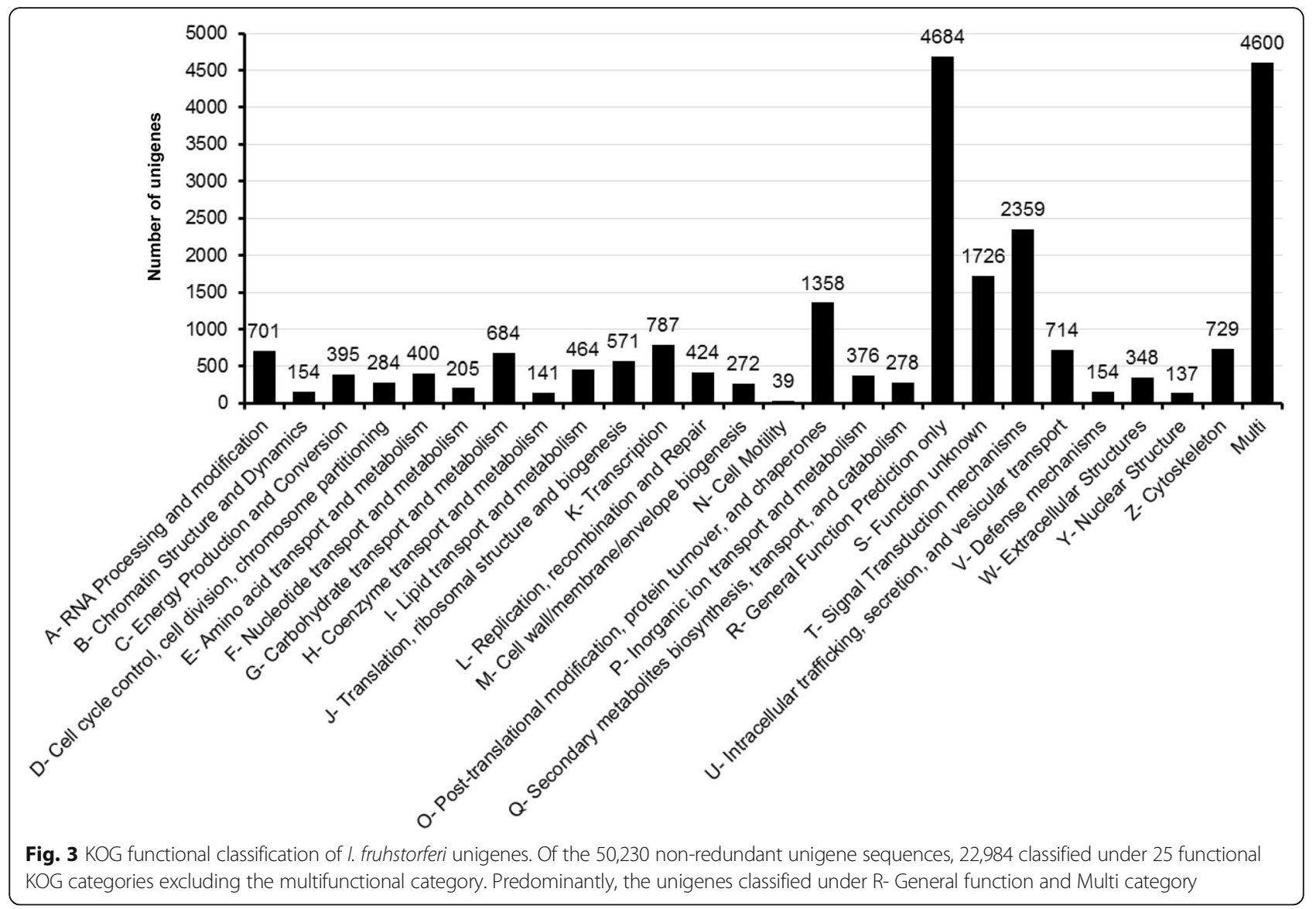

hAT-Charlie and TcMar-Tigger, Simple repeats, and Low complexity regions. Under the SINEs, ALU (7 elements) and MIR repeat (4 elements) occupied lengths of 1593 and $253 \mathrm{bp}$, respectively. LINE repeats such as LINE1, LINE2, and L3/CR1 repeats were found occupying lengths of $11,676 \mathrm{bp}, 822 \mathrm{bp}$, and $1196 \mathrm{bp}$, respectively. Among the retrotransposons, lesser number of LTR elements were found as compared to the non-LTR LINE elements. In the present study, the 50,230 assembled unigene sequences were screened for SSR markers using MISA (MicroSAtellite identification tool) (Table 6). A total of 4822 SSRs were identified in 3888 unigene sequences with 700 sequences containing more than 1 SSR. These SSRs were then classified on the basis of number of repeats to di-, tri-, tetra-, penta-, and hexanucleotide repeats. Mononucleotide repeats were not considered for analysis due to the possibility of homopolymer formation during Illumina sequencing. A maximum of dinucleotide repeats were noticed followed by trinucleotides and tetranucleotide repeats. Dinucleotide repeats existed in maximum six iterations, trinucleotides in maximum five iterations, tetraand pentanucleotide repeats in maximum of four iterations. Further, in an attempt to classify the SSR repeat types, it was found that the dinucleotide repeat AT/AT (1107 SSR) and AC/GT (814 SSR) were the most predominant. Among the trinucleotide repeats, ATC/ATG and AAG/CTT with 698 and 446 SSRs were the dominant. AACC/GGTT and AGAT/ATCT repeats with 158 and 136 SSRs were the dominant tetranucleotide repeats. A summary of SSR repeat types is shown in Fig. 5.

\section{Candidate genes in I. fruhstorferi immune defense system}

A keyword search composed of a series of representative innate immunity and oxidative stress genes was used to screen candidate unigenes putatively responsible for $I$. fruhstorferi immune defense. The GO term and KEGG classification also provided sufficient information regarding the representative genes classified under "immune system". An exhaustive summary of the candidate genes under immune defense categories such as 'pathogen recognition receptor (PRR)', 'TLR signalling pathway,' 'adaptor proteins', 'MyD88-dependent pathway', 'endogenous ligands', 'immune effectors', 'antimicrobial peptides', 'cytokines and cytokine receptors', 'apoptosis-related factors', and 'others' are summarized (Additional file 5: Table S2). Overall, we were able to retrieve the extensive repertoire of genes that could be relevant to understand the molluscan innate immune signalling process and the specific host defense system against pathogens. Furthermore, genes involved in the unique features of the slug's 


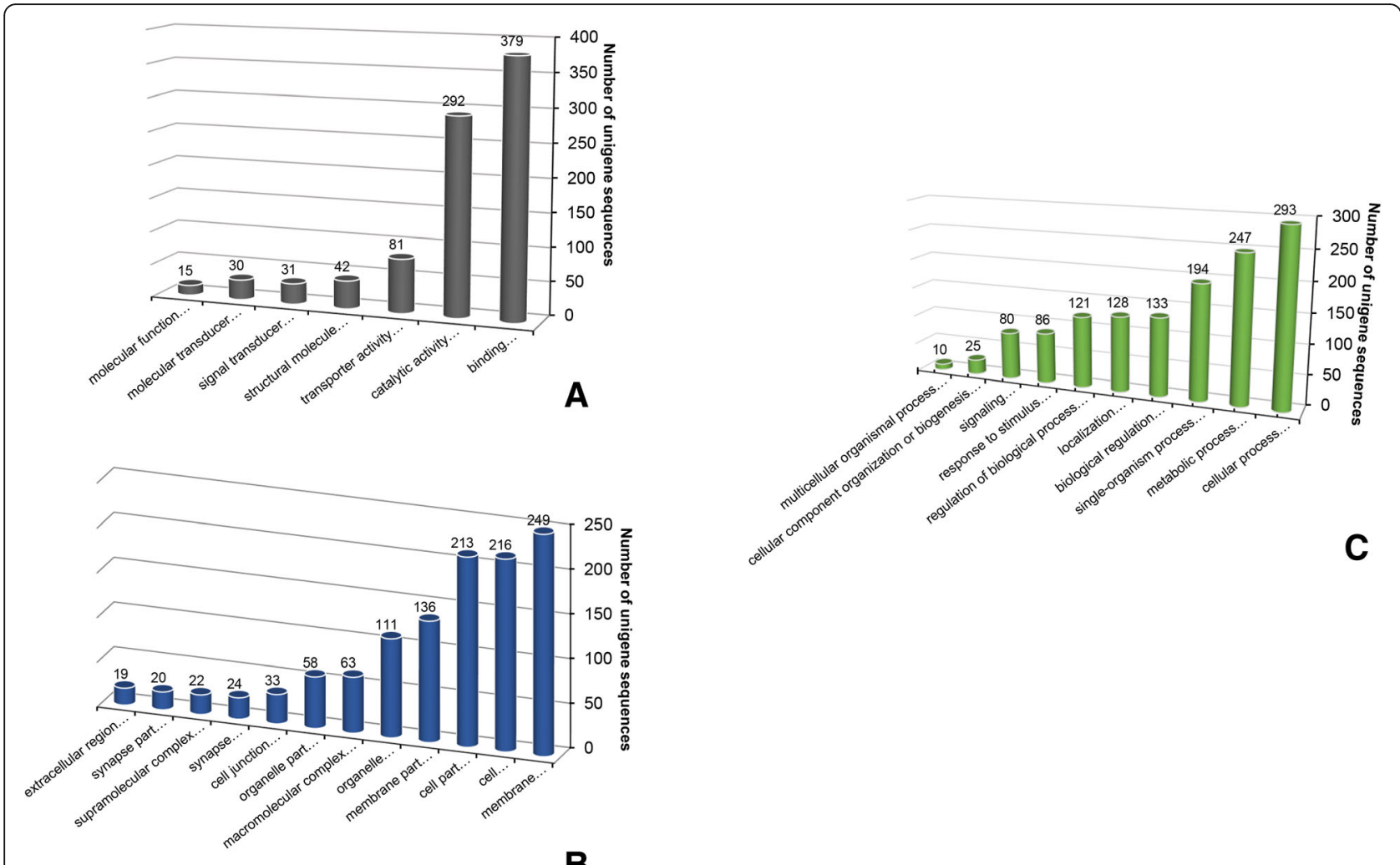

B

Fig. $4 \mathrm{GO}$ classification of I. fruhstorferi unigenes at level 2. The unigene sequences classified under different functional categories under the GO term notation of (a) Molecular Function, (b) Cellular Component, and (c) Biological Process

physiology have been summarized in Table 7 . We would like to emphasize that the screening of heat shock protein and the aquaporin family genes from I. fruhstorferi transcriptome can be scaled-up for functional genomics approaches to understand the physiological rules of adaptation in the species.

From the transcriptome survey of I. fruhstorferi, we have screened unigenes homologous to PRRs such as the Toll-like receptors (TLRs), C-type lectins (CTLs), other lectin classes (I-type lectin, Malectin, Collectin, Selectin, Galectin), fibrinogen-related proteins (FRPs), and scavenger receptors (SRs), among others. Further, we have targeted the Tollip (IfTollip) and the Peptidoglycan Recognition Protein-SC2 (IfPGRP_SC2) for an elaborate in silico analysis covering the conserved domain architecture and phylogenetic position among orthologs. Further, to prove the accuracy of transcriptome results (validation of gene assembly and annotation), a PCRsequencing based approach targeting IfTollip and IfPGRP-SC2 were successfully used. The sequences of PCR products thus obtained were aligned with the screened unigenes representing the target genes, revealing 100\% identity (Additional file 6: Figure S4). This study did not include the functional characterization of IfTollip and IfPGRP_SC2 due to the difficulties in maintaining the experimental model and limited sample availability. We predicted the full-length ORF and the translated amino acid sequence of I. fruhstorferi Tollip (IfTollip) using bioinformatics analysis (Additional file 7: Figure S5). The IfTollip ORF composed of $840 \mathrm{bp}$ encoding a polypeptide of 279 amino acids. The predicted molecular weight of IfTollip is $31.38 \mathrm{kDa}$, with an isoelectric point (pI) of 6.21. Multiple sequence alignment of Tollips from representative invertebrate and vertebrate species followed by SMART domain analysis revealed three conserved domains including Tom-1 binding domain (TBD), conserved core domain 2 (C2), and coupling of ubiquitin to endoplasmic reticulum degradation (CUE) domain (Additional file 8: Figure S6). Secondary structure prediction of IfTollip showed two and three $\alpha$-helices at the $\mathrm{N}$-terminal and the $\mathrm{C}$-terminal (CUE domain), respectively (Additional file 9: Figure S7). The C2 domain was conspicuously represented by $\beta$-sheets and connecting loops. Furthermore, a phylogenetic tree was constructed using full-length amino acid sequences of Tollip from other species (Fig. 6). IfTollip was grouped closer to Tollips from molluscs showing most close association with B. glabrata and A. californica. This suggests that the evolutionary position of Tollip is conserved across phylum. 
Table 4 KEGG Pathway distribution

\begin{tabular}{ll}
\hline KEGG pathways & $\begin{array}{l}\text { Enzymes in Sequences } \\
\text { the pathway of enzymes }\end{array}$ \\
\hline
\end{tabular}

Environmental Information Processing

Signal transduction

Phosphatidylinositol signalling system

2

Metabolism

Amino acid metabolism

Alanine, aspartate and glutamate metabolism

Arginine biosynthesis

Cysteine and methionine metabolism

Phenylalanine metabolism

Phenylalanine, tyrosine and tryptophan biosynthesis

Biosynthesis of other secondary metabolites

Neomycin, kanamycin and gentamicin biosynthesis

Streptomycin biosynthesis

Carbohydrate metabolism

Amino sugar and nucleotide sugar metabolism

Citrate cycle (TCA cycle)

Fructose and mannose metabolism

Galactose metabolism

Glycolysis / Gluconeogenesis

Glyoxylate and dicarboxylate metabolism

Inositol phosphate metabolism

Pentose and glucuronate interconversions 1

Starch and sucrose metabolism

Energy metabolism

Carbon fixation in photosynthetic

organisms

Nitrogen metabolism

Global and overview maps

Biosynthesis of antibiotics

Glycan biosynthesis and metabolism

Mucin type O-glycan biosynthesis

$\mathrm{N}$-Glycan biosynthesis

Other glycan degradation

Various types of N-glycan biosynthesis

Metabolism of cofactors and vitamins

Folate biosynthesis

Porphyrin and chlorophyll metabolism

Thiamine metabolism

Metabolism of terpenoids and polyketides

Terpenoid backbone biosynthesis
Table 4 KEGG Pathway distribution (Continued)

\begin{tabular}{lll}
\hline KEGG pathways & $\begin{array}{l}\text { Enzymes in } \\
\text { the pathway }\end{array}$ & $\begin{array}{l}\text { Sequences } \\
\text { of enzymes }\end{array}$ \\
\hline Nucleotide metabolism & 5 & 41 \\
$\quad$ Purine metabolism & & \\
Xenobiotics biodegradation and metabolism & & 3 \\
Aminobenzoate degradation & 1 & 1 \\
$\quad$ Drug metabolism - other enzymes & 1 & \\
Organismal Systems & & \\
Immune system & & 5 \\
T cell receptor signalling pathway & 2 & 2 \\
Th1 and Th2 cell differentiation & 1 & \\
\hline
\end{tabular}

In I. fruhstorferi transcriptome, we located a putative PGRP-SC homolog (If_PGRP_SC-2) comprising of $519 \mathrm{bp}$ ORF encoding a protein of 172 amino acid residues (Additional file 10: Figure S8). If_PGRP_SC2 showed a predicted molecular mass of $19 \mathrm{kDa}$ and a theoretical isoelectric point of 6.75. In silico analysis of the protein sequence revealed the characteristic overlapping of the PGRP and $\mathrm{N}$-acetylmuramoyl-L-alanine amidase domains (amidase_2 domain). Further, If_PGRP_SC2 lacked a signal peptide sequence. Multiple sequence comparisons (Additional file 11: Figure S9) revealed the conserved amidase activity motifs $\left(\mathrm{Zn}^{2+}\right.$ - binding sites at His-40, Tyr-75, His-149, and Cys-155), and the disulphide bridges. Our results reveal that 'If_PGRP_SC2' like other insect PGRPs are crosslinked with a single disulphide bond. Further, the residues utilized for DAP-type PGN binding (Gly-60, Trp-61, and Arg-80) are found to be conserved. If_PGRP_SC2 protein shows three $\alpha$-helices and five $\beta$-strands based on predictive secondary structure analysis (Additional file 12: Figure S10). According to the phylogenetic analysis If_PGRP_SC-2 was closely clustered with Physella acuta PGRP and B. glabrata PGRP-SC with a strong bootstrap support (Fig. 7). Further, we have deciphered the TLR signalling cascade hypothesized for I. fruhstorferi in Fig. 8 (detailed in the discussion section).

Among the prime endogenous ligands, all classes of HSPs have been found in the I. fruhstorferi transcriptome including the HSP70, HSP90, HSP60, small HSPs, hypoxia-inducible factors and stress-induced phosphoprotein. We also identified enzymes involved in reactive oxygen species (ROS) and reactive nitrogen intermediate (RNI) pathways, including the dual oxidase (DUOX), superoxide dismutase (SOD), glutathione peroxidase (GPx), Nitric oxide synthase (NOS), catalase (CAT), peroxiredoxin, glutathione synthetase and glutathione-s-transferase. Furthermore, classes of cathepsins and lysozyme were also noticed, that could participate in the phagocytic defense mechanisms in the pulmonate species. Enzymes that maintain balance at the level of ROS produced and removed 
Table 5 RepeatMasker based analysis of repeating elements in the Incilaria fruhstorferi unigenes

\begin{tabular}{|c|c|c|c|c|}
\hline \multirow{4}{*}{ SINEs: } & & Number of elements ${ }^{a}$ & Length occupied & Percentage of sequence \\
\hline & & 12 & $1932 \mathrm{bp}$ & $0.00 \%$ \\
\hline & ALUs & 7 & $1593 \mathrm{bp}$ & $0.00 \%$ \\
\hline & MIRs & 4 & $253 \mathrm{bp}$ & $0.00 \%$ \\
\hline \multirow[t]{4}{*}{ LINES: } & & 642 & $125,258 \mathrm{bp}$ & $0.19 \%$ \\
\hline & LINE1 & 78 & $11,676 \mathrm{bp}$ & $0.02 \%$ \\
\hline & LINE2 & 14 & $822 \mathrm{bp}$ & $0.00 \%$ \\
\hline & L3/CR1 & 19 & $1196 \mathrm{bp}$ & $0.00 \%$ \\
\hline \multirow[t]{5}{*}{ LTR elements: } & & 28 & $5015 \mathrm{bp}$ & $0.01 \%$ \\
\hline & ERVL & 6 & $435 \mathrm{bp}$ & $0.00 \%$ \\
\hline & ERVL-MaLRs & 4 & $248 \mathrm{bp}$ & $0.00 \%$ \\
\hline & ERV_class I & 8 & $3489 \mathrm{bp}$ & $0.01 \%$ \\
\hline & ERV_class II & 6 & $501 \mathrm{bp}$ & $0.00 \%$ \\
\hline \multirow[t]{3}{*}{ DNA elements: } & & 283 & $47,370 \mathrm{bp}$ & $0.07 \%$ \\
\hline & hAT-Charlie & 122 & $15,876 \mathrm{bp}$ & $0.02 \%$ \\
\hline & TcMar-Tigger & 55 & $7272 \mathrm{bp}$ & $0.01 \%$ \\
\hline \multicolumn{2}{|l|}{ Unclassified: } & 2 & $102 \mathrm{bp}$ & $0.00 \%$ \\
\hline \multicolumn{2}{|c|}{ Total interspersed repeats: } & & $179,677 \mathrm{bp}$ & $0.27 \%$ \\
\hline \multicolumn{2}{|l|}{ Small RNA: } & 55 & $4190 \mathrm{bp}$ & $0.01 \%$ \\
\hline \multicolumn{2}{|l|}{ Satellites: } & 26 & $15,698 \mathrm{bp}$ & $0.02 \%$ \\
\hline \multicolumn{2}{|l|}{ Simple repeats: } & 9067 & $407,633 \mathrm{bp}$ & $0.60 \%$ \\
\hline \multicolumn{2}{|l|}{ Low complexity: } & 1481 & $77,420 \mathrm{bp}$ & $0.11 \%$ \\
\hline
\end{tabular}

${ }^{a}$ most repeats fragmented by insertions or deletions have been counted as one element

RepBase Update 20,160,829; RM database version 20,160,829

includes the antioxidant enzymes screened from the I. fruhstorferi transcriptome such as SOD (superoxide dismutase, $\mathrm{Cu}-\mathrm{Zn}$ like, $\mathrm{Cu}$-like and $\mathrm{Mn}$-like), CAT (catalase), and GPx-7 (glutathione peroxidase). The redox proteins screened include thioredoxin, thioredoxin-1, thioredoxin domain containing protein- $3,-5,-9,-12,-15,-16,-17$,

Table 6 Screening of Simple Sequence Repeats (SSRs) from unigene sequences of Incilaria fruhstorferi

\begin{tabular}{ll}
\hline Total number of sequences examined & 50,230 \\
\hline Total size of examined sequences (bp) & $67,667,335$ \\
Total number of identified SSRs & 4822 \\
Number of SSR containing sequences & 3888 \\
Number of sequences containing more than 1 SSR & 700 \\
Number of SSRs present in compound formation & 471 \\
Unit size & Number of SSRs \\
2 & 2335 \\
3 & 1738 \\
4 & 704 \\
5 & 40 \\
6 & 5 \\
\hline
\end{tabular}

peroxiredoxin-2, $-4,-5,-6$, glutaredoxin-2, and -3 . Considering the conserved status of the antioxidant defense mechanisms in molluscs including the components identified in the present study, we confirm the existence of a potent defense system guarding against ROS and RNIs.

Furthermore, 22 transcripts of cathepsins belonging to $\mathrm{B}, \mathrm{L}, \mathrm{F}, \mathrm{Z}$, and $\mathrm{O}$ forms have been screened from the $I$. fruhstorferi transcriptome. Incilarin $\mathrm{A}$ and $\mathrm{B}$ showing homology to animal C-type lectins were also screened in the present study. We found transcripts of caspases, Baculoviral IAP repeat containing proteins (IAPs), apoptotic inducible factors (AIF), apoptosis regulator, apoptosis inhibitor 1, Bax, and Bcl-2 from the de novo analysis of $I$. fruhstorferi transcriptome.

\section{Candidate genes related to sex determination and reproduction}

The sex determination genes identified from the transcriptome includes the high mobility group (HMG) domain proteins, transcription factor Sox-2, protein MAB-21, Wnt, beta-catenin 1, Wilms tumor protein 1, GADD45, and armadillo proteins (Additional file 13: Table S3). Further, we made a comparative analysis of sex-related regulatory transcripts from Mus musculus 


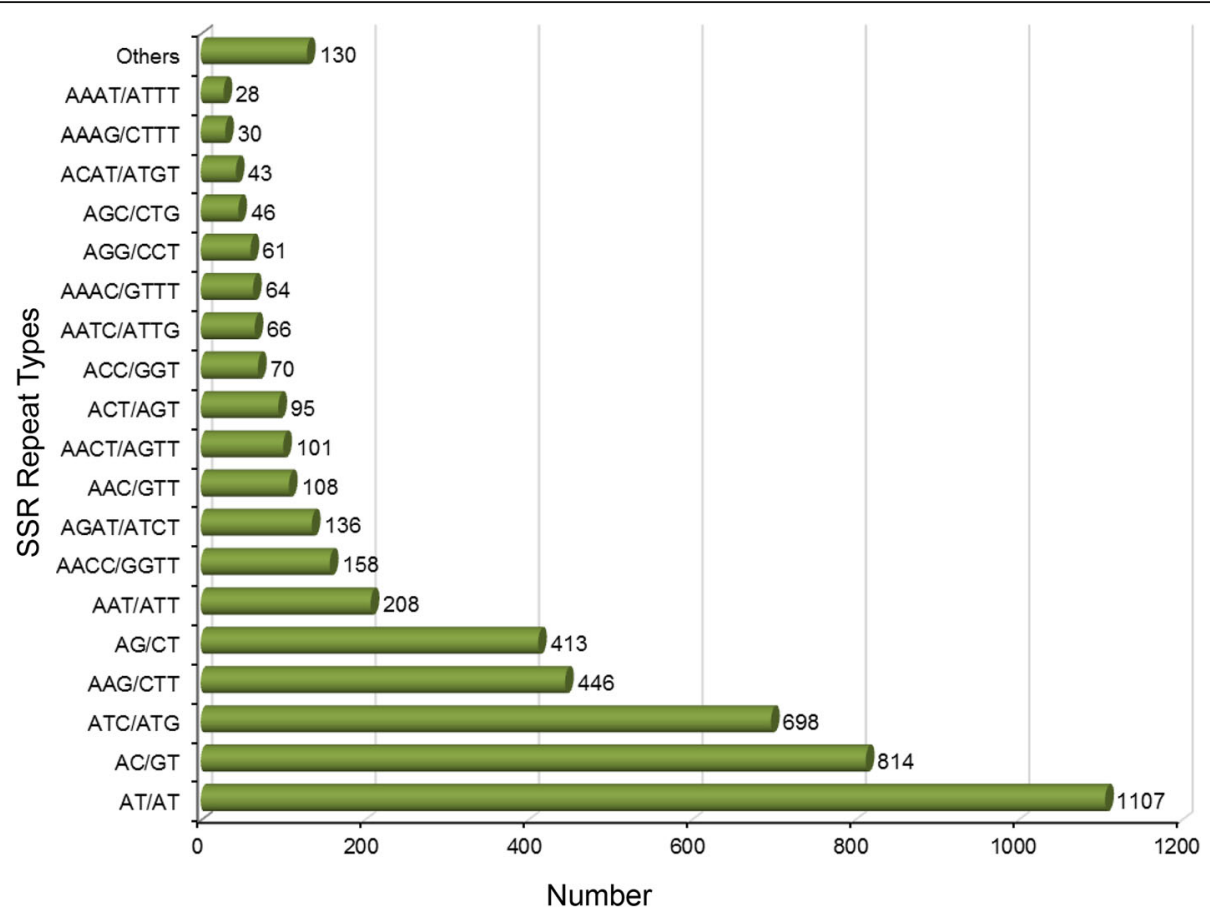

Fig. 5 Distribution of Simple Sequence Repeat (SSR) types found in the unigenes of I. fruhstorferi. The most predominant repeat types included the dinucleotides AT/AT and AC/GT

(mouse), Drosophila melanogaster (fly), Caenorhabditis elegans (worm), C. hongkongensis (oyster), and I. fruhstorferi (Table 8). The mammalian homologues of Sox, GATA-binding protein (GATA), ATP-dependent helicase (ATRX), Hedgehog acyltransferase (Hhat), Growth arrest and DNA damage inducible protein 45 (GADD45), RSpondin 1, Sex determining protein fem, and Wilms tumor protein 1 (WT1) were detected in Incilaria transcriptome.

Under the reproduction-related transcripts, we identified unigenes related to sperm flagellar protein, spermatogenesis-associated protein, sperm surface protein, spermidine synthase, spermine oxidase, sperm-associated antigens, testis expressed sequences, vitellogenin, and kinases in the present study (Additional file 13: Table S3). In the Incilaria transcriptome, sperm associated antigen $-1,-6,-7,-16$, and -17 were noticed. The overall scope of sex-determination and reproduction related genes from the air-breathing land slug, I. fruhstorferi provides substantive evidence for understanding the molluscan sex-development and differentiation.

\section{Candidate genes related to growth and muscle development}

In the present study, transcriptome characterization identified transcripts putatively related to the somatotrophic axis and muscle growth in I. fruhstorferi. The candidate genes related to somatotrophic axis includes insulin-related peptide, epidermal growth factor receptor, mollusk derived growth factor, adenosine deaminase and other transcription factors (Additional file 14: Table S4). Further, we identified transcripts such as actin, profilin, tropomyosin related to muscle growth and other transcripts such as chitinase, collagen, apolipophorins, dermatopontins, perlucin and calcitonin related to overall growth and development. Here, we have identified transcripts putatively related to actin, actin-1, actin-2-like, actin-5C-like, and actin-related protein-3, - 5, - 6, and -8 . We also found profilin-like and profilin-4-like transcripts involved in the restructuring of the actin cytoskeleton. It is speculated that profilins could regulate actin cytoskeleton through the control of actin polymerization. In the present study, we have also identified some proteins of unknown function in muscle growth. Hence, further studies at the single-gene level are warranted for more information on the regulatory mechanisms underlying growth and development in molluscs. This information would certainly advance the knowledge of candidate growth biomarkers related to molluscan development.

\section{Discussion}

The construction of a complete mRNA-seq library was considered necessary for the characterization of regulatory transcripts in I. fruhstorferi, a pulmonate slug species with restricted distribution. The slug species has not 
Table 7 Genes of interest related to Adaptation/Physiology in the land slug, Incilaria fruhstorferi

\begin{tabular}{|c|c|c|}
\hline Candidate genes & Unigenes ID & Length (bp) \\
\hline Angiotensin-converting enzyme-like & If_Uni_08052, If_Uni_10667, If_Uni_38048 & $2711,2722,2206$ \\
\hline $\begin{array}{l}\text { Type-1 angiotensin II receptor-associated } \\
\text { protein-like }\end{array}$ & If_Uni_23153 & 1732 \\
\hline Type-1 angiotensin II receptor B-like & If_Uni_28079, If_Uni_28268 & 2354,2158 \\
\hline Adenylate cyclase isoform $\mathrm{X}_{1}$ & If_Uni_27752, If_Uni_27753 & 4405,4152 \\
\hline Adenylate cyclase type 2-like & If_Uni_27754, If_Uni_35219 & $2008,2381,1192$ \\
\hline Adenylate cyclase & $\begin{array}{l}\text { If_Uni_30138, If_Uni_32170, If_Uni_32295, } \\
\text { If_Uni_35390, If_Uni_36571 }\end{array}$ & $2381,1826,2164,400,1026$ \\
\hline 5'-AMP-activated protein kinase & $\begin{array}{l}\text { If_Uni_06408, If_Uni_10162, If_Uni_16111, } \\
\text { If_Uni_17195, If_Uni_31806, If_Uni_45007, } \\
\text { If_Uni_45226, If_Uni_49689 }\end{array}$ & $509,2981,1583,5849,1937,1110,1134,416$ \\
\hline Aquaporin, partial & If_Uni_13477, If_Uni_36565, If_Uni_43198 & $2249,934,2384$ \\
\hline Aquaporin-4-like & $\begin{array}{l}\text { If_Uni_27284, If_Uni_27285, If_Uni_40352, } \\
\text { If_Uni_48767 }\end{array}$ & $2280,2132,475,1184$ \\
\hline Aquaporin AQPcic-like & If_Uni_30154, If_Uni_30155 & 1320, 1807 \\
\hline Aquaporin-8-like & If_Uni_30734 & 1971 \\
\hline Aquaporin AQPAn.G-like & If_Uni_37263, If_Uni_49973 & 1378,1468 \\
\hline Aquaporin-9-like & If_Uni_39587 & 1799 \\
\hline Collagen alpha-1(I) chain-like & $\begin{array}{l}\text { If_Uni_08744, If_Uni_08745, If_Uni_09485, } \\
\text { If_Uni_09486, If_Uni_15928, If_Uni_27766, } \\
\text { If_Uni_27767, If_Uni_29582, If_Uni_34918, } \\
\text { If_Uni_37761, If_Uni_39405, If_Uni_39724 }\end{array}$ & $\begin{array}{l}2643,3984,2558,1269,9047,6483,6691,1652, \\
1063,2081,434,2112\end{array}$ \\
\hline NMDA-type glutamate receptor & If_Uni_38285 & 1269 \\
\hline Glutamate receptor ionotropic, NMDA 2B-like & If_Uni_41604 & 278 \\
\hline Heat shock protein 70 B2-like & $\begin{array}{l}\text { If_Uni_09052, If_Uni_09053, If_Uni_23324, } \\
\text { If_Uni_23325, If_Uni_23326 }\end{array}$ & $1926,3457,2146,2550,2635$ \\
\hline Heat shock $70 \mathrm{kDa}$ protein cognate 4 & $\begin{array}{l}\text { If_Uni_23327, If_Uni_23328, If_Uni_33435, } \\
\text { If_Uni_43426 }\end{array}$ & $2338,2197,2643,2749$ \\
\hline Heat shock 70 kDa protein 4 & If_Uni_42286 & 4176 \\
\hline Heat shock $70 \mathrm{kDa}$ protein 10 & If_Uni_43360 & 285 \\
\hline Heat shock $70 \mathrm{kDa}$ protein 13 & If_Uni_36140, If_Uni_43584 & 879,609 \\
\hline Heat shock $70 \mathrm{kDa}$ protein 14 & If_Uni_22068, If_Uni_22069, If_Uni_22070 & $1324,4415,4727$ \\
\hline Hsp70-binding protein 1 & If_Uni_41490 & 2947 \\
\hline Insulin receptor substrate 1 & If_Uni_44383 & 1014 \\
\hline Mitogen-activated protein kinase 15 & If_Uni_28827, If_Uni_28829 & 2104,2417 \\
\hline $\begin{array}{l}\text { calcium-independent phospholipase } \\
\text { A2-gamma-like }\end{array}$ & If_Uni_28664, If_Uni_28665, & $3187,1485,3167$ \\
\hline group XV phospholipase A2-like & If_Uni_31585 & 1836 \\
\hline $\begin{array}{l}85 / 88 \mathrm{kDa} \text { calcium-independent phospholipase } \\
\text { A2-like }\end{array}$ & If_Uni_32679, If_Uni_38324, If_Uni_41729 & 4506,4556 \\
\hline stimulated by retinoic acid gene 6 protein & $\begin{array}{l}\text { If_Uni_26478, If_Uni_26479, If_Uni_26480, } \\
\text { If_Uni_26481, If_Uni_27267, If_Uni_27367, } \\
\text { If_Uni_27368, If_Uni_27369, If_Uni_33908, } \\
\text { If_Uni_46952 }\end{array}$ & $\begin{array}{l}2296,2213,2242,2205,1938,2115,2198,2107, \\
2373,626\end{array}$ \\
\hline T-box transcription factor TBX20-like & If_Uni_21931, If_Uni_34429 & 3972,1103 \\
\hline T-box transcription factor TBX1-B-like & $\begin{array}{l}\text { If_Uni_25334, If_Uni_25335, If_Uni_03651, } \\
\text { If_Uni_03826 }\end{array}$ & $2118,1639,2069,2148$ \\
\hline Solute carrier family 41 & $\begin{array}{l}\text { If_Uni_07293, If_Uni_24931, If_Uni_24932, } \\
\text { If_Uni_24933, If_Uni_24934, If_Uni_24935, } \\
\text { If_Uni_24936, If_Uni_35601 }\end{array}$ & $625,2009,2388,2628,1942,2923,2472,978$ \\
\hline
\end{tabular}


Table 7 Genes of interest related to Adaptation/Physiology in the land slug, Incilaria fruhstorferi (Continued)

\begin{tabular}{|c|c|c|}
\hline Candidate genes & Unigenes ID & Length (bp) \\
\hline Solute carrier family 25 & $\begin{array}{l}\text { If_Uni_08851, If_Uni_08852, If_Uni_08853, } \\
\text { If_Uni_08854, If_Uni_08855, If_Uni_10412, } \\
\text { If_Uni_15275, If_Uni_15276, If_Uni_15277, } \\
\text { If_Uni_15278, If_Uni_18168, If_Uni_30488, } \\
\text { If_Uni_09808, If_Uni_33449, If_Uni_33450, } \\
\text { If_Uni_34586, If_Uni_35960, If_Uni_38390, } \\
\text { If_Uni_40358, If_Uni_41902, If_Uni_45240, } \\
\text { If_Uni_47602, If_Uni_48696, If_Uni_00611 }\end{array}$ & $\begin{array}{l}2061,2136,2163,2157,2185,1962,3220,3019, \\
2473,2614,1212,1614,1552,2559,1424,1249 \\
956,767,1736,944,822,505,1512,2039\end{array}$ \\
\hline Solute carrier family 40 & $\begin{array}{l}\text { If_Uni_09262, If_Uni_09263, If_Uni_22596, } \\
\text { If_Uni_22597, If_Uni_30690 }\end{array}$ & $2419,2212,3284,3739,1694$ \\
\hline Solute carrier family 43 & $\begin{array}{l}\text { If_Uni_09267, If_Uni_09268, If_Uni_37142, } \\
\text { If_Uni_43186, If_Uni_06623 }\end{array}$ & 2046, 1893, 2929, 2355, 2393 \\
\hline Solute carrier family 22 & $\begin{array}{l}\text { If_Uni_10312, If_Uni_15224, If_Uni_19826, } \\
\text { If_Uni_22045, If_Uni_24463, If_Uni_24464, } \\
\text { If_Uni_24465, If_Uni_24466, If_Uni_24467, } \\
\text { If_Uni_24468, If_Uni_24469, If_Uni_26545, } \\
\text { If_Uni_28975, If_Uni_28976, If_Uni_32419, } \\
\text { If_Uni, If } \\
\text { If_Uni_32420, If_Uni_34348, If_Uni_36091, } \\
\text { If_Uni_36557, If_Uni_36908, If_Uni_37399, } \\
\text { If_Uni_37943, If_Uni_43214, If_Uni_49180, } \\
\text { If_Uni_50058, If_Uni_00679, If_Uni_04935 }\end{array}$ & $\begin{array}{l}2182,1013,1576,326,2087,2244,2088,1748 \\
2140,3025,1801,2738,1543,2640,945,612,687 \\
758,551,1147,1086,1172,272,450,1259,236,300\end{array}$ \\
\hline Solute carrier family 23 & $\begin{array}{l}\text { If_Uni_12119, If_Uni_36506, If_Uni_37977, } \\
\text { If_Uni_40499, If_Uni_47883 }\end{array}$ & $2100,699,2314,2418,1370$ \\
\hline Solute carrier family 35 & $\begin{array}{l}\text { If_Uni_12656, If_Uni_12657, If_Uni_14403, } \\
\text { If_Uni__9966, If_Uni_27046, If_Uni_27993, } \\
\text { If_Uni_29331, If_Uni_29332, If_Uni_32495, } \\
\text { If_Uni_35319, If_Uni_39687, If_Uni_46340, } \\
\text { If_Uni_49558, If_Uni_00045, If_Uni_06869 }\end{array}$ & $\begin{array}{l}1525,1417,2119,1745,3306,2026,676,1184, \\
1375,1347,1611,791,1075,1160,1455\end{array}$ \\
\hline Solute carrier family 12 & $\begin{array}{l}\text { If_Uni_15628, If_Uni_15629, If_Uni_15630, } \\
\text { If_Uni_15631, If_Uni_17088, If_Uni_17089, } \\
\text { If_Uni_24560, If_Uni_24561, If_Uni_24562, } \\
\text { If_Uni_24563, If_Uni_24564, If_Uni_24565, } \\
\text { If_Uni_24566, If_Uni_24902, If_Uni_24903, } \\
\text { If_Uni_24904, If_Uni_28839, If_Uni_30662, } \\
\text { If_Uni_39565, If_Uni_45407, If_Uni_48974 }\end{array}$ & $\begin{array}{l}4001,3652,4273,4107,3486,1747,3201,3299,2542, \\
3349,3300,3498,3172,4000,5098,6979,1660,2388, \\
713,1364,1204\end{array}$ \\
\hline Solute carrier family 28 & $\begin{array}{l}\text { If_Uni_19488, If_Uni_19489, If_Uni_19743, } \\
\text { If_Uni_24733, If_Uni_24734, If_Uni_24735, } \\
\text { If_Uni_26540, If_Uni_26541, If_Uni_26542 }\end{array}$ & $2683,2556,3035,9234,5184,9389,2972,2846,3184$ \\
\hline Solute carrier family 15 & $\begin{array}{l}\text { If_Uni_27273, If_Uni_28577, If_Uni_30039, } \\
\text { If_Uni_30040, If_Uni_31286, If_Uni_31287, } \\
\text { If_Uni_32935, If_Uni_39335 }\end{array}$ & $2378,2135,2193,1741,3147,3270,1729,357$ \\
\hline Solute carrier family 46 & If_Uni_32274, If_Uni_43893 & 2899,368 \\
\hline Solute carrier family 13 & If_Uni_34257, If_Uni_43800, If_Uni_48035 & $595,552,361$ \\
\hline Solute carrier family 45 & If_Uni_36376 & 1546 \\
\hline
\end{tabular}

been categorized under the protective list of faunal biodiversity. This makes the slug population more susceptible towards habitat degradation and environmental perturbations. The basic idea of this study was to explore the fitness traits regulating adaptation and survival of the species in the wild. The microsatellite markers directly found on the expressed transcripts is considered useful for population diversity assessment and markerassisted breeding. For the processing of I. fruhstorferi transcriptome, we used the Illumina Hi-Seq 4000 platform with paired-end reads layout. Further, we considered FastQC statistics and Cutadapt data for an initial quality assessment of Illumina sequencing data as these are the preferred choices to arrive at clean datasets (with Phred quality $\geq$ Q20) $[12,32,33]$. To get the non-redundant unigenes, the clean reads were assembled using the Trinity platform and clustered using the TGICL package. The unigenes were further explored for the functional annotation and microsatellite identification. The average length of unigenes obtained in this study was higher compared to the transcriptome assembly of other molluscs, including Cristaria plicata (737.1) [12], Satsuma myomphala (571.7 bp) [11], Aegista chejuensis/Aegista quelpartensis (735.4/705.6) [18] and Pinctada maxima (407 bp) [34].

As a measure of quality, we characterized the completeness of the assembly using BUSCO assessment tool. 


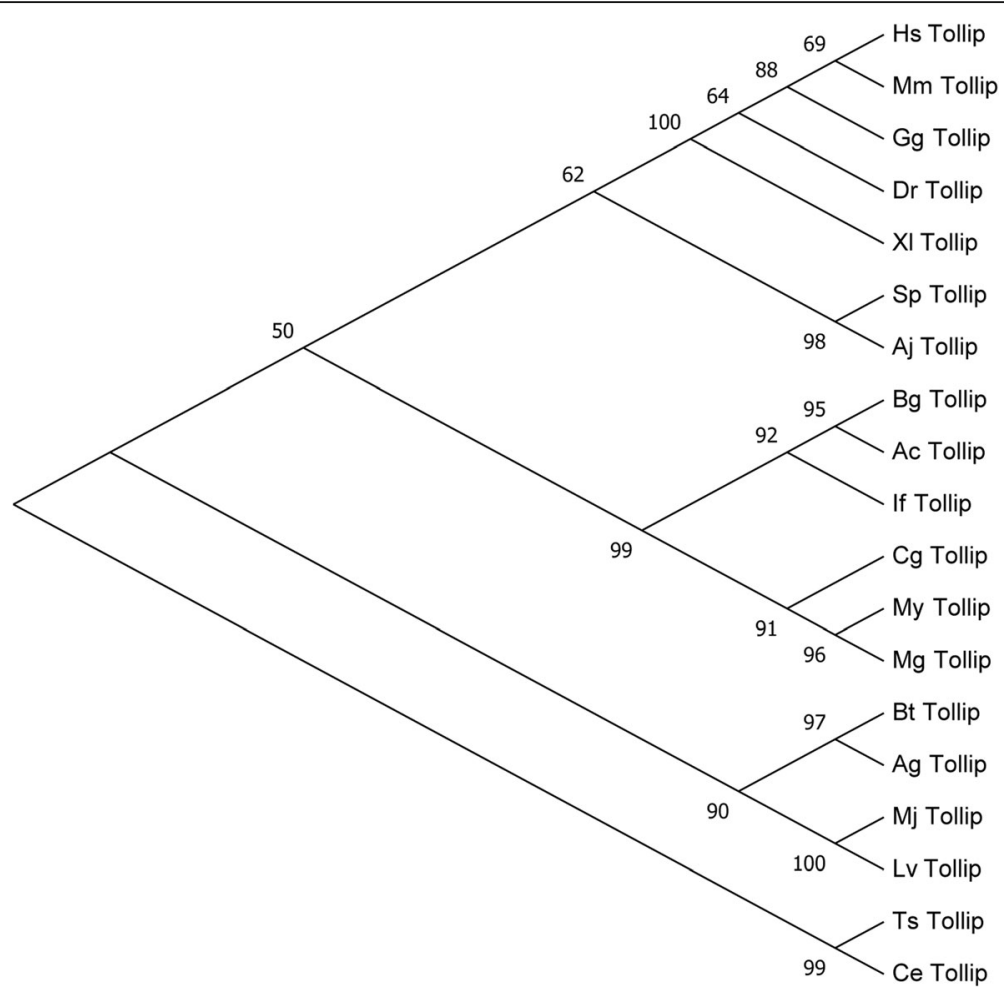

Fig. 6 Phylogenetic relationships inferred for IfTollip using the maximum-likelihood method of MEGA7 program. The evolutionary distances were computed using the Poisson correction method. The tree was bootstrapped (1000 replications) and the values are indicated by numbers at nodes. GenBank accession numbers downloaded from Ensembl and NCBI are: HsTollip, Q9H0E2.1; MmTollip, Q9QZ06; GgTollip, F1P006; XITollip, Q3B8H2;AjTollip, AHA83602.1; AgTollip, XP_562476; MjTollip, BAK19511; LvTollip, AET79206; CgTollip, EKC34473; MgTollip AHI17285; CeTollip, NP_492757; SpTollip, XP_001196148; DrTollip, AAH46009.1; PyTollip, AK062848.1; TsTollip, XP_003379806.1; BgTollip, XP_013073937.1 and AcTollip XP_012936924.1

BUSCO employs a set of genes selected from major species clade at the OrthoDB catalogue of orthologues. We were able to capture the complete expected gene content in case of Incilaria transcriptome, wherein at least $91.8 \%$ were single-copy and complete BUSCO and only $3.1 \%$ missing BUSCO. Our transcriptome assembly statistics showed a lower number of complete and duplicated BUSCOs when compared with transcriptome assembly of black tiger shrimp Penaeus monodon [35]. Further, when considering the annotation of $I$. fruhstorferi unigenes, PANM database (Protostome database covering the protein sequences from Nematoda, Arthropoda, and Mollusca groups) was considered prominent. Most homologous sequence hits in the de novo transcriptome analysis of non-model organisms such as the pearl mollusc C. plicata [12], land snails Aegista chejuensis and Aegista quelpartensis [18], and the diving beetle Cybister chinensis [36] were observed with the homologous sequences in PANM-DB. The top-hit species distribution against the PANM-DB sequences was found biased towards completely sequenced genomes. This is the reason for over-representation of A. californica (19,945 protein-coding genes) and B. glabrata
(25,539 protein-coding genes) genomic sequences. The top-hit species distribution analysis is common for the annotation of non-model species with very little or no genomic information available. Further, the lack of slug genomics data is reflected in the absence of related species sequences from the BLAST results.

The functional annotation of I. fruhstorferi unigenes using the InterPro conserved domain search revealed the most conspicuous zinc finger, protein-kinase, immunoglobulin-fold, and carbohydrate-binding domains. The most classical $\mathrm{C} 2 \mathrm{H} 2 \mathrm{Znfs}$ are known to have versatile functions, including DNA (DNA-binding domains of transcription factors), RNA, and protein contacts [37]. Our results support transcriptome studies in the land snail, Satsuma myomphala [11] and the pearl bivalve, C. plicata [12], wherein the $\mathrm{C} 2 \mathrm{H} 2 \mathrm{Znfs}$ were found to be the most conserved domain with representations of immunoglobulin-like fold domain. Protein kinase-like domain attributes critical phosphorylation functions to the intracellular protein kinases related to signal extrapolation during key metabolic, cellular, or immune processes. Immunoglobulin-like and EGF-like fold domains commonly provide interaction surfaces to other proteins via their beta-sheets [38]. 


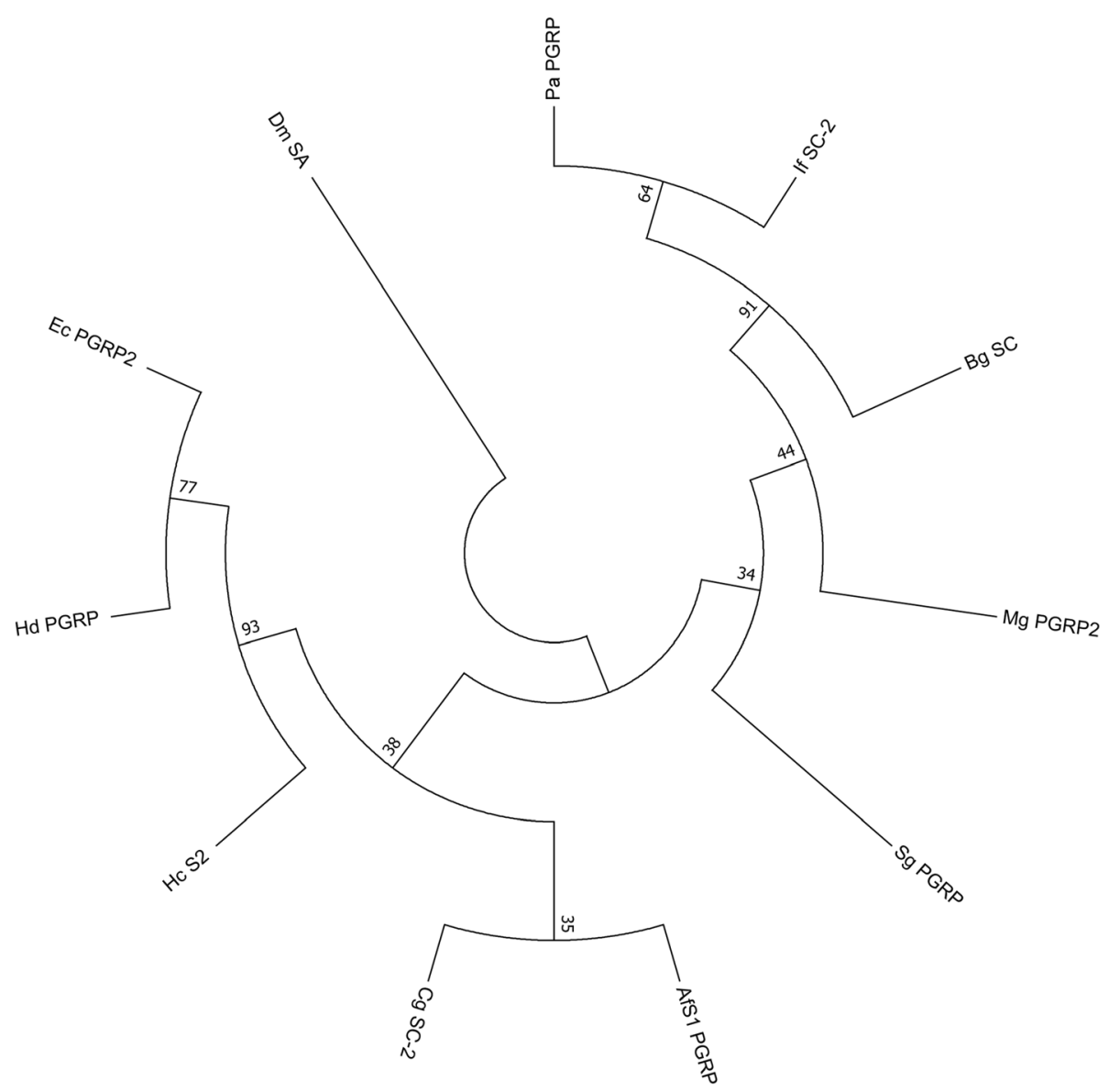

Fig. 7 Phylogenetic analysis of If_PGRP_SC-2. The PGRP domain was considered for the analysis using the maximum likelihood method of MEGA7 program. The tree was bootstrapped (1000 replications) and the values are indicated by numbers at the nodes. The GenBank accession numbers are:: Pa_PGRP, No. JF831447.1; Bg_SC, No. XM_013209309.1; Sg_PGRP, No. JN642118.1; Hd_PGRP, No. KF554145.1; EC_PGRP2, No. AY956812.1; HC_S2, No. KF941201.1; AfS1_PGRP, No. AY987008.1; Cg_SC-2, No. XM_01 1424461.2; Mg_PGRP2, No. KP125936.1 and Dm_SA, No. AF207540.1

Galactose-binding domains are properties of lectins and are conspicuously found in several molluscan species including the mussel Mytilus galloprovincialis [39], Eastern oyster Crassostrea virginica [40], and the Manila clam Ruditapes phillippinarum [41]. The KOG-based classification is also routinely used for functional descriptor analysis of newly sequenced genomes. [42]. The KOG database, first created in 1997, has gone through several updates, and currently has significant genome coverage. Our results support earlier reports of KOG classification analysis in molluscs such as in the Asian clam, Corbicula fluminea [43], pearl bivalve, C. plicata [12], and the land snail, S. myomphala [11]. GO annotations are based on evidences presented in the form of GO 'evidence codes'. Generally, evidence code distribution shows the overrepresentation of 'electronic' annotations that are not genetically tested, hence may infer higher false positives. Therefore, it is to be concluded with reference to GO annotations that the interpretation of unigenes relates only to the 'predicted' function. The predominant evidence codes distributed for I. fruhstorferi unigenes were IEA (inferred from electronic annotation), and hence either homology-based and/or other experimental or sequence information. The GO classification represented in the present study showed similarities to the GO term annotations for Crassostrea hongkongensis [44] and C. plicata [12]. Again, KEGG is a unified database connecting genomic information to biological pathways and provides a foresight towards the putative enzymes in the genome of the species [45].

Repeatmasker is used to screen DNA sequences for repeating elements or low complexity regions. These include interspersed repeats, including retroelements and DNA transposons [46]. Especially, the retroelements make up a family of transposons proposed to have important roles in adaptive processes. These elements are under sufficient selective pressure following environmental stress and could be attributed to specific adaptations across the taxa. These elements are the forerunners for genetic variation and contributors to phenotypic plasticity $[47,48]$. Further, 


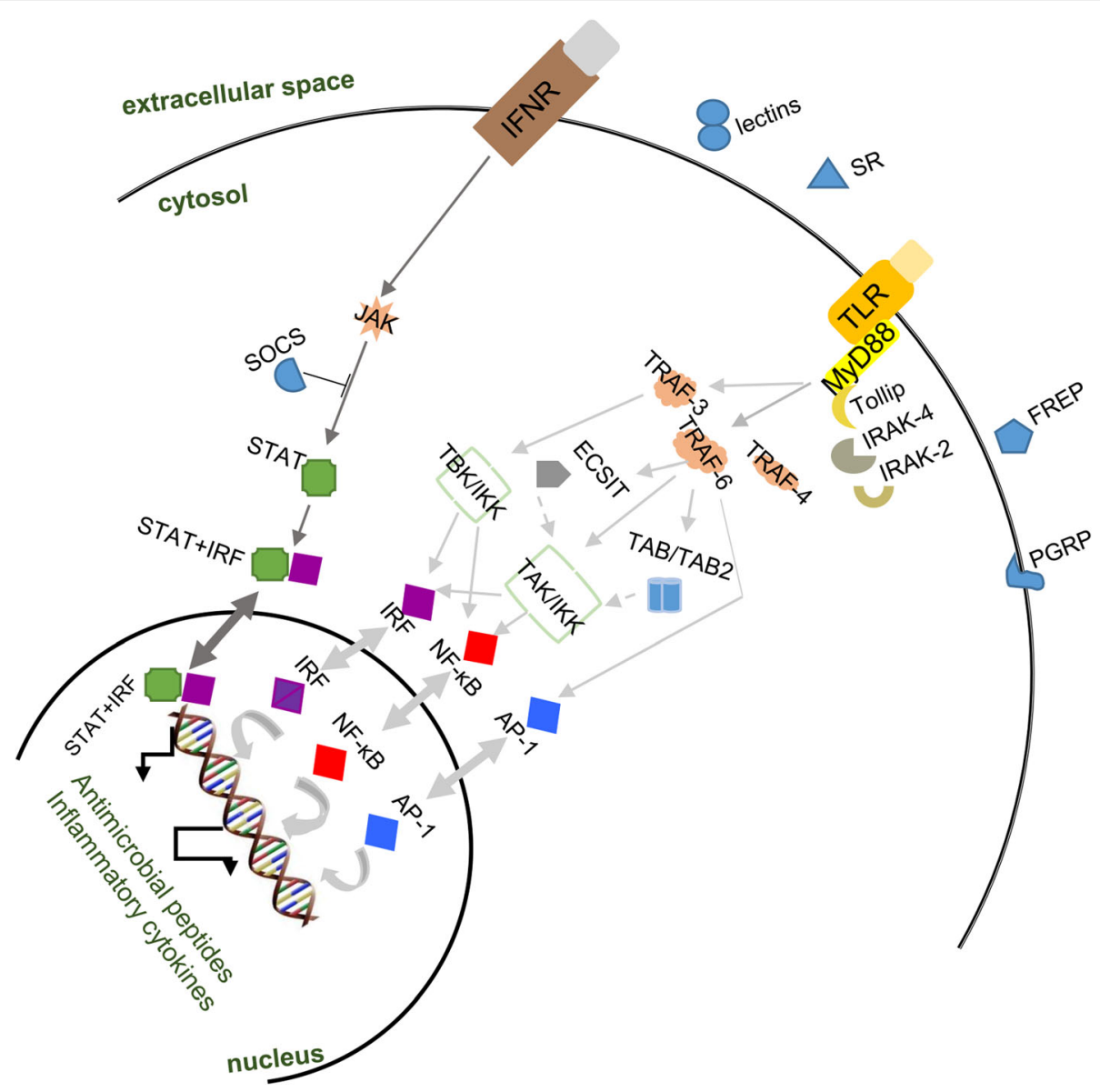

Fig. 8 The schematic representation of TLR and JAK-STAT pathways postulated in the slug I. fruhstorferi. IFNR, interferon receptor; JAK, janus kinase; SOCS, suppressor of cytokine signaling; STAT, signal transducer and activator of transcription; IRF, interferon regulatory factor; SR, scavenger receptors; FREP, fibrinogen-related protein; PGRP, peptidoglycan recognition protein; IRAK, interleukin-1 receptor-associated kinase; TRAF, tumor necrosis factor receptor associated factor; ECSIT, evolutionarily conserved signaling intermediate in Toll pathway; TAB, tumor growth factor-beta-activated kinase; TBK, TANK-binding kinase; IKK, IKB kinase; TAK, transforming growth factor-beta activated kinase; NF-KB, nuclear factor kappa B; AP, activator protein

the discovery of microsatellites from transcriptomics analysis of non-model species has gained momentum in the last decade due to the direct presence of these polymorphisms in the coding sequence and its transferability function. These microsatellites would represent annotated markers within genes that could be directly related to abiotic and biotic stressors [49]. Largely, the traditional methodologies of marker mining such as the enrichment of genomic DNA libraries, followed by clone sequencing has been replaced with the more reliable, high-throughput, and cost-efficient Next Generation Sequencing (NGS) based transcriptome characterization [50, 51]. SSRs and Single Nucleotide Polymorphism (SNP) markers screened from transcriptomics analysis of non-model species is currently applied at the field for genetic diversity assessments and population structure dynamics having wider applicability in conservation genomics. Consistent with our results, the dinucleotide repeats were the most abundant repeats in the transcriptomics profile of other molluscan species such as the endangered land snail, S. myomphala [11], endangered Neritid mollusc, Clithon retropictus [52], and oyster, C. hongkongensis [44].

At the level of molluscan transcriptome, very few reports have addressed the immune defense systems so as to make an effective adjudication of the immune surveillance mechanism against biotic and abiotic stressors. The only information on genes and pathways related to innate immune system has been reported in the endangered freshwater pearl bivalve, C. plicata [12], Mediterranean mussel, Mytilus galloprovincialis [53], and gastropod, Rapana venosa [54]. With the transcriptome information of the pulmonate slug, I. fruhstorferi now available in the public domain (https://www.ncbi.nlm.nih.gov/sra/SRX3096547[accn]), greater thrust would be laid on the functional characterization of immunity and physiology-attributed genes. As the case with molluscs, self/non-self-discrimination can be considered as the most fundamental step in invertebrate immunity. With molluscans establishing 
$\begin{array}{ll}\text { Patnaik et al. BMC Genomics } & \text { (2019) 20:154 }\end{array}$

Page 18 of 26

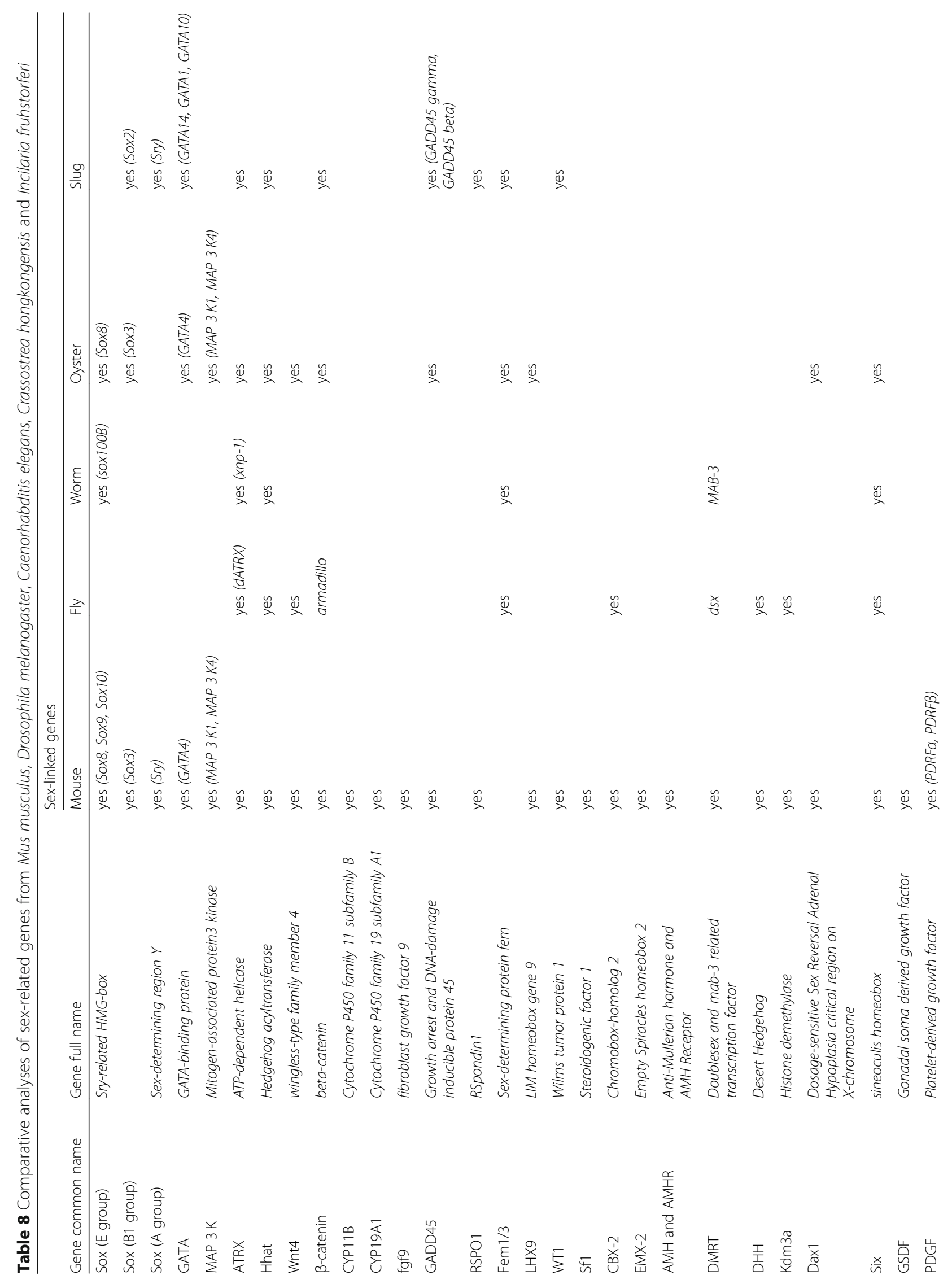




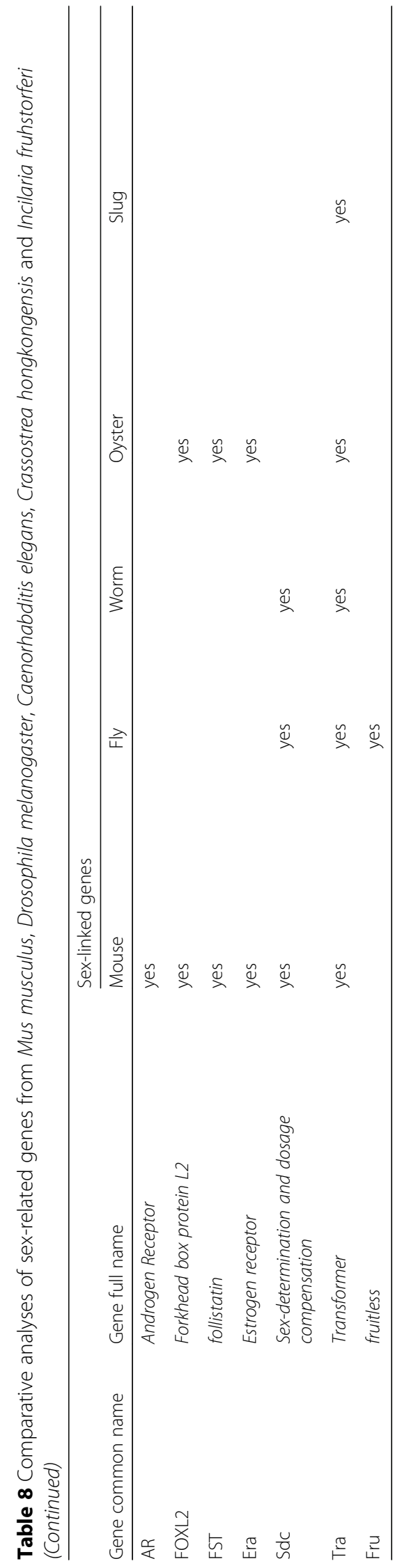


niches in diverse habitats, ecological adaptation is vital to overall sustainability of species in the wild. Pathogen recognition receptors (PRRs) show great diversity in establishing one-to-one contact with pathogen-associated molecular patterns (PAMPs) at the extracellular, membrane, or intracellular surfaces, modulating immune signaling pathways related to the humoral defense response [55, 56]. We considered the full-length ORFs of Tollip and PGRP_SC2 obtained from Incilaria transcriptome for a detailed understanding of the putative immune signaling cascade. Tollip is an intracellular partner for TLR signaling cascade elements. In the IL-1R pathway, Tollip blocks Interleukin-1 receptor associated kinase-1(IRAK-1) phosphorylation, thus checking the IL-1 induced signaling. Further, Tollip directly interacts with TLR2 or TLR4 to negatively regulate TLR induced signaling by a similar mechanism [57]. Tollip has been cloned and characterized from Yesso scallop Patinopecten yessoensis (PyTollip), [58] grouper Epinephelus tauvina [59], crustacean Litopenaeus vannamei [60], and sea cucumber Apostichopus japonicus [61]. The predicted ORF sequence of I. fruhstorferi Tollip gene (IfTollip) was smaller than PyTollip (867 bp ORF encoding 288 amino acids) [58]. Among the conserved domains represented in Tollip are the $\mathrm{C} 2$ domain and the CUE domain. The conserved motifs of $\mathrm{C} 2$ domain included the basic residues at positions 87 (Arg), 132 (Arg), and 144 (His) responsible for Phosphaditylinositol-3 phosphate (PtdIns3P) and Phosphatidylinositol-1,4 diphosphate [PtdIns $(4,5) \mathrm{P}_{2}$ ] recognition and binding [62]. The CUE domain comprised of the conserved 'Met-Phe-Pro' sequence responsible for ubiquitin binding [63, 64]. This is true in most cases, however, according to a previous report, Tollip structure is more unstable in primates compared to arthropod groups suggesting selective pressure at the residue-level in higher organisms [65]. Peptidoglycan Recognition Proteins (PGRPs) bind to peptidoglycan present in the cell surface of bacteria promoting lysis and/ or phagocytosis of the cell $[66,67]$. PGRPs (both long and short forms) have been identified in few molluscan species such as Haliotis discus discus [68], Solen grandis [69], Argopecten irradians [70], and Chlamys farreri [71]. Six short form PGRPs with conserved amidase activity have been revealed from Crassostrea gigas genome [72]. The lack of a signal peptide in the I. fruhstorferi PGRP_SC2 (If_PGRP_SC2) was in agreement to the short PGRPs screened from the EST database of deep- sea mussel, Bathymodiolus azoricus (Ba-PGRP 2 and Ba-PGRP 4) [73]. Further, the predicted secondary structure analysis for If_PGRP_SC2 show consistency with the three-dimensional model of BaPGRP 2 [73] and Drosophila PGRP-LB residues [74].

A large repertoire of PRRs including lectins, scavenger receptor (class F), Down syndrome cell-adhesion molecule (DSCAM), thioester-containing proteins (TEPs),
PGRP, and fibrinogen-related proteins (FREPs) have been screened from I. fruhstorferi transcriptome. An expansion in the PRR repertoire is expected as large number of genome and transcriptome sequencing projects involving molluscan species have been completed [72]. However, the discovery of scavenger receptor family of PRRs has been limited with only reports from oyster Pinctada martensii and scallop C. farreri [75]. We have identified scavenger receptor class F member from I. fruhstorferi transcriptome. In any case, PRRs have developed an extensive network of self/non-self-discrimination in molluscs defining flexible and specific responses to microbial challenges. This provides survival advantage to the molluscs in the absence of adaptive immune mechanisms. An understanding of the TLR signaling pathway is relevant in the context of Incilaria species transcriptome as this would be a reference for molecular immunologists to excavate the adaptation mechanisms in the wild populations. We have suggested a predictive model for the TLR signaling pathway in $I$. fruhstorferi. The TLR signaling pathway is the most promiscuous among molluscs with genes identified and putative functions annotated in model and non-model species [76-78]. TLRs bind with PAMPs and elicit MyD88-dependent or independent signaling pathway. The MyD88 dependent pathway has been well known in molluscan immunity. In this case, TNF (tumor necrosis factor) receptor-associated factor 6 (TRAF6)/TRAF3 is recruited in the cytosol upon activation of the TLR-MyD88 signaling cascade. MyD88dependent TLR pathway is involved in apoptosis and antimicrobial functions and have been identified in molluscs including C. farreri, M. galloprovincialis, and Cyclina sinensis $[79,80]$. TRAF3 is proposed to mediate intranuclear signal processing through TANK-binding kinase 1 (TBK1)-mediated phosphorylation of interferon regulatory factor (IRF). IRF is translocated to the nucleus where it elicits the expression of inflammatory cytokines (type I IFN). IFNs activate the Janus activated kinase -signal transducer and activator of transcription (JAK-STAT) signaling pathway [81]. We have screened IRF1, STAT2, STAT4, STAT5 as putative transcription factors mediating JAK-STAT signaling and suppressor of cytokine signaling 5 (SOCS5) as negative regulator of the pathway. Further, TRAF6 mediated NF-kB signaling via transforming growth factor-beta activated kinase (TAK) and activator protein 1 (AP1) signaling has been proposed for $I$. fruhstorferi. A mitochondrial-like ECSIT (evolutionarily conserved signaling intermediate in Toll pathway) has also been screened that could collect signals from TRAF6 resulting in the generation of reactive oxygen species (ROS). Further, an indirect interaction may exist for ECSIT eliciting NF-kB signaling. TRAF6 mediated NF-kB signaling via tumor-growth factor beta activated kinase $1 / 2$ (TAB1/TAB2) can also be postulated from the current 
study. Our findings are in agreement with similar studies in Zhikong scallop C. farreri [82], and S. glomerata [14]. Furthermore, contrary to genome of oyster species such as $S$. glomerata and C. gigas, we were unable to screen the components of mitochondrial antiviral signaling protein (MAVS)-dependent RIG-I-like receptor (RLR) signaling pathway, indispensable for antiviral immunity in the molluscs. To sum up, besides the core elements of Toll and JAK-STAT signaling pathway, accessory components such as Tollip, IL-1 receptor-associated kinase (IRAK) were also identified in the present study, indicating the completeness of signaling pathways in I. fruhstorferi. Furthermore, the HSPs (preferentially HSP70 and HSP90 class) activate kinases and are regarded as negative and positive regulators of NF-kB signaling [83, 84]. In case of freshwater molluscs, Bellamya bengalensis and Lamellidans marginalis inducible NOS (iNOS) have been associated with phagocytic activity [85], while DUOX has been known to be expressed in non-phagocytic cells such as the gills in oyster, C. gigas and the scallop, $M$. yessoensis in response to heavy metals [86]. Earlier, we have discussed the TRAF6-ECSIT pathway for mitochondrial ROS generation through the TLR-MyD88 signaling pathway in the species. Besides roles in innate immunity ROS are also implicated in oxidative stress signaling, apoptosis, cell growth and differentiation [87]. In agreement to our results, cathepsin transcripts have also been identified from S. glomerata transcriptome [14] and hemocytes of mussel, C. plicata [88] and oyster C. virginica [89]. Cathepsin Z (CTSZ) is a lysosomal product and is implicated in immune reactions against bacteria such as Vibrio parahaemolyticus, Listeria monocytogenes, and bacterial cell surface carbohydrates such as LPS in disk abalone, Haliotis discus discus [90]. Transcripts coding for lysozyme and bactericidal permeability-increasing protein (BPI) in I. fruhstorferi confirms the presence of bactericidal activity as an additional means of immune defense. The full-length transcript of metallothionein gene has been studied in I. fruhstorferi for understanding the phylogeny of the species under the molluscan clade [91]. Considering the apoptosis cascade and in agreement to apoptosis core components deciphered for Incilaria species, it could be speculated that AIF could drive apoptosis in a caspase-dependent manner in the molluscan species [92]. Apaf-1 mediated apoptotic cascade seems absent in the molluscs and since apaf- 1 has not been observed in any other mollusc, the apoptotic cascades might work independent of apaf-1. Among the extrinsic apoptosis pathway components, TNF- $\alpha$ factor in association with TNF receptor-associated factor could recruit several caspases. This lay credence to the importance of apoptotic mechanisms in I. fruhstorferi health and sustainability in the wild. The cataloguing of immune-related functional transcripts from the de novo assembled transcriptome of the air- breathing pulmonate $I$. fruhstorferi clearly provides a defense screen that could be exploited for research on molluscan adaptation and survivability in the wild.

Sex differentiation is indirectly influenced by environmental factors such as light, temperature, nutritional conditions, and reproductive physiology of the species. Moreover, over evolutionary periods, genetic effects of sex determination have accumulated. Transcriptome resources could be vital to direct the discovery of specific pathways of sex determination and successful reproduction strategies. Gonadal transcriptome analysis in molluscan species has identified candidate genes involved in sex-determination/ differentiation and reproduction for commercial exploitation of molluscs on one hand [44, 93, 94] and informed conservation planning of the threatened and endangered species on the other hand [12]. This is the first exhaustive study towards identification of molecular mechanisms underpinning reproduction in the hermaphroditic slug species. An information on the regulatory genes associated with the reproductive biology of male and female sections of Incilaria species would be significant towards interpreting the population structure dynamics and conservation of germplasm. As Incilaria is a hermaphrodite, the spermatozoa and ova are produced in an ovotestis, and released through a single hermaphroditic duct. Hence, the species was not sexed for transcriptome characterization. The transcripts of sex-determining protein fem-1 (feminization-1) largely populated in the Incilaria transcriptome were also detected in C. plicata [12], Haliotis discus hannai [95], and P. margaritifera transcriptome [93]. This transcript is one of the many associated with hermaphrodite phenotypes in Caenorhabditis elegans [96]. The Sox family of transcription factors involved in the regulation of development and differentiation of germ cells have been identified in a number of invertebrates [97]. In blood clam, Tegillarca granosa, Sox homologues (Sox2, Sox8, Sox9, and Sox14) with significant difference in gene expression between males and females have been identified [94]. In the transcriptome of $C$. plicata, the HMG-box domain family members included Sox5, Sox6, Sox9, Sox11, Sox15, and SoxB2 [12]. Sox30, defined to be involved in the differentiation of male gametes was found to be highly expressed in the testis of the Manila clam $R$. philippinarum [98]. Homologs of $\beta$-catenin was screened from the I. fruhstorferi transcriptome. $\beta$-catenin activation leads to the synthesis of female sex-determining pathway. The armadillo (ARM) repeat region in molluscs is a $\beta$-catenin ortholog reported in C. hongkongensis, C. gigas, and C. farreri $[44,99,100]$. Several ARM proteins (ARM- $1,-2,-3,-4,-6,-7,-8$ ) were discovered in I. fruhstorferi transcriptome. Homologs of Wilms tumor protein 1 (WT-1) identified from the current study could essentially activate the anti-mullerian hormone receptor essential for mammalian urogenital development. Homologs of WT-1 and anti-mullerian 
hormone were not reported from the oyster, C. hongkongensis [44]. Although, the homologs of vertebrate DMRT (Doublesex and MAB-3 transcription factor) were identified from the C. gigas and C. plicata transcriptome [12, 44], it was not evident in the C. hongkongensis and Incilaria transcriptome. Further, our results are consistent to the screening of reproduction-associated transcripts in $C$. plicata [12] and the land snail, S. myomphala [11]. Spermatogenesis-associated protein 6 was found highly expressed in male tissues of the abalone $H$. discus hannai playing a role in flagellar mortality [95]. Most of the transcripts found are suggested to be associated with male reproductive tissues. Sperm flagellar protein 2, spermassociated antigen 16 and 17, spermatogenesis associated protein 1 and 4, and testis-specific serine threonine protein kinase were identified from the scallop, Nodipecten subnodosus by suppressive subtractive hybridization and pyrosequencing [101].

Genes related to growth and muscle development is necessary as it provides an informed decision in aquaculture breeding programs towards the selection of fitness genes for improved performance of domesticated stocks. Further with the advent of genomics technologies, gene function on expressed quantitative trait locus phenotypes has provided valuable fundamental knowledge to be applied to molecular assisted breeding programs [102]. It has also facilitated genomics approaches for improved understanding of molecular mechanisms involved in growth. Gene discovery in non-model species using the nextgeneration sequencing platforms has been successful in cataloguing transcripts with fundamental roles in growth and muscle development, including actin, myosin, and tropomyosin $[103,104]$. Our results are consistent with the findings in the South African abalone species, Haliotis midae wherein insulin-like growth factors and insulin-like growth factor binding proteins has improved the growth pertinent to aquaculture breeding [105]. The growth factors play critical role in the development of somatotrophic axis and form the skeletal muscle in finfishes [106]. Molluscan insulin-related peptide is involved in glucose metabolism and growth as well as the regulation of germ cell proliferation and maturation [107]. The molluscan insulin-related peptide has been identified from other molluscs such as the snail, Lymnaea stagnalis [108], bivalve, Patinopecten yessoensis [109], slug, A. californica [110], and the garden slug, Deroceras reticulatum [111]. Considering the muscle growth in molluscs, actin gene is critical in contraction, cell signaling and establishment and management of cell junctions and has been isolated from A. californica [112], Haliotis species [113, 114], Chlamys farreri [115], and Rapana venosa [116].

\section{Conclusions}

In this study, we assembled the transcriptome of land slug, I. fruhstorferi, and described candidate genes involved in immunity, sex, and growth. The assembled transcriptome was considered complete by BUSCO method. Considering that this air-breathing slug is an important node in the food web with restricted habitats, the intactness of different immune signalling modes and adaptation-related genes could provide for a compelling evidence for informed conservation planning. Furthermore, identification of microsatellites repeats/markers in the coding regions would be crucial for discovering the species in newer habitats, exploring distribution ranges and study of population diversity.

\section{Additional files}

Additional file 1: Table S1. Pre-processing of raw reads obtained from Incilaria fruhstorferi transcriptome using Illumina Next-Generation sequencer. (DOCX $13 \mathrm{~kb}$ )

Additional file 2: Figure S1. Homology statistics of I. fruhstorferi unigenes against PANM DB. BLASTx annotation of the unigenes to PANM $\mathrm{DB}$ at an E-value threshold of 1.0E-5 was used for the statistical summary. (A) E-value distribution, (B) Identity distribution, (C) Similarity distribution, (D) Sequence hits/non-hits correlated to the length of unigenes. (TIF 771 $\mathrm{kb})$

Additional file 3: Figure S2. Distribution of top-hit species in PANM DB matched to I. fruhstorferi visceral mass unigenes using BLASTx. An E-value cutoff of 1.0E-5 was utilized for the homology matching. Quite predictably, the highest matches are observed with the molluscan model, Aplysia californica. (TIF $566 \mathrm{~kb}$ )

Additional file 4: Figure S3. Gene Ontology (GO) based functional mapping of I. fruhstorferi unigenes. (A) Venn diagram showing the distribution of unigenes to three $\mathrm{GO}$ function categories, viz. Biological Process, Cellular Component, and Molecular Function, (B) Number of unigenes assigned to GO terms per sequence. (DOCX 13 kb) (TIF 607 kb)

Additional file 5: Table S2. Classification of Incilaria fruhstorferi candidate genes to the innate immune signaling process. (DOCX 26 kb)

Additional file 6: Figure S4. Validation of the I. fruhstorferi transcriptome assembly and annotation using PCR-sequencing approach. (A) RT-PCR analysis of the whole-body sample using gene-specific primers. M: 100 bp DNA marker; lane-1: 207 bp Tollip gene product; lane2: PGRP-SC2 gene product; lane-3: actin-2 gene product. (B) Clustal X2 based pairwise alignment of transcriptome-derived Tollip sequence and PCR-product sequence. (C) Clustal X2 based alignment of transcriptomederived PGRP-SC2 member and PCR product sequence. (TIF $1682 \mathrm{~kb}$ )

Additional file 7: Figure S5. The full-length nucleotide sequence for $I$. fruhstorferi Tollip (Toll interacting protein; IfTollip). The predicted ORF with the translated protein sequence is boxed. The conserved C2 and CUE domain of Tollip protein is shown in orange and blue colors, respectively. (TIF 757 kb)

Additional file 8: Figure S6. Multiple sequence alignment (MSA) of the amino acid sequence of IfTollip protein with representative Tollip amino acid sequences from invertebrates and vertebrates. The alignment was conducted using Clustal X2 (version 2.0) and represented with GeneDoc. The internal and terminal gaps are represented by dashes. The highly conserved C2 and CUE domains are shown using orange and green arrows. Asterisks indicate the conserved residues in the $\mathrm{C} 2$ domain responsible for Ptdlns3P and Ptdlns $(4,5) P_{2}$ recognition and binding. The conserved ubiquitin-binding motifs found in the CUE domain are boxed. (TIF $2504 \mathrm{~kb}$ ) 
Additional file 9: Figure S7. Secondary structure prediction of IfTollip using PSIPHRED (version 3.3). Cylinders in pink represent alpha helices, yellow bars represent beta strands and black lines represent coils. (TIF $384 \mathrm{~kb}$ )

Additional file 10: Figure S8. The full-length nucleotide sequence for 1 . fruhstorferi Peptidoglycan Recognition Protein SC-2 (If_PGRP_SC-2). The predicted ORF with the translated protein sequence is boxed. The conserved PGRP and overlapping amidase_2 domains are underlined. (TIF $742 \mathrm{~kb}$ )

Additional file 11: Figure S9. Multiple sequence alignment (MSA) of the amino acid sequence underlying the conserved PGRP domain of If_PGRP_SC-2 protein with representative amino acid sequences from other invertebrates. The alignment was conducted using Clustal X2 (version 2.0) and represented using graphical user interface. The black and grey regions indicate the positions of amino acid identity and similarity, respectively. The residues boxed are associated with recognition of Diaminopimelic acid-type (DAP-type) PGN. $\mathbf{\Delta}: \mathrm{Zn}^{2+}$ binding sites, s: cysteines predicted to form disulphide bridges. (TIF $1684 \mathrm{~kb}$ )

Additional file 12: Figure S10. Secondary structure prediction of If_PGRP_SC-2 using PSI-PRED (version 3.3). Cylinders in pink represent alpha helices, yellow bars represent beta strands and black lines represent coils. (TIF $295 \mathrm{~kb}$ )

Additional file 13: Table S3. Candidate Sex-Determination and Reproduction related genes from I. fruhstorferi unigenes. (DOCX $20 \mathrm{~kb}$ )

Additional file 14: Table S4. Genes of interest related to growth in the land slug, Incilaria fruhstorferi. (DOCX $22 \mathrm{~kb}$ )

\section{Abbreviations}

AIF: Apoptosis inducing factor; AP: Activator protein; ARM: Armadillo-repeat region; ATRX: ATP-dependent helicase; BLAST: Basic local alignment search tool; BPI: Bactericidal permeability-increasing protein; BUSCO: Benchmarking universal single-copy orthologs; CAT: Catalase; COI: Cytochrome oxidase I: CTL: C-type lectins; CUE: Coupling of ubiquitin conjugation to endoplasmic reticulum degradation; DMRT: Double-sex and MAB-3 transcription factor; DSCAM: Down syndrome cell-adhesion molecule; DUOX: Dual-oxidase; ECSIT: Evolutionarily conserved signalling intermediate in Toll pathway; FREP: Fibrinogen-related proteins; GO: Gene ontology; GPx: Glutathione peroxidase; HSP: Heat shock proteins; IRAK: Interleukin-1 associated kinase; IRF: Interferon regulatory factors; JAK-STAT: Janus kinase-signal transducers and activators of transcription; KEGG: Kyoto encyclopaedia of genes and genomes; KOG: Clusters of orthologous groups; LINE: Long interspersed nuclear elements; LTR: Long-terminal repeats; MEGA: Molecular Evolutionary Genetics Analysis; MISA: Microsatellite identification tool; MyD88: Myeloid differentiation factor88; NCBI: National Centre for Biotechnology Information; NOS: Nitric oxide synthase; ORF: Open reading frame; PAMP: Pathogenassociated molecular patterns; PANM-DB: Protostome database; PCR: Polymerase chain reaction; PE: Paired-ends; PGRP: Peptidoglycan recognition protein; PRR: Pattern recognition proteins; RNI: Reactive nucleotide intermediates; ROS: Reactive oxygen species; RT: Reversetranscriptase; SINE: Short interspersed nuclear elements; SNP: Single nucleotide polymorphism; SOCS: Suppressor of cytokine signalling; SOD: Superoxide dismutase; SR: Scavenger receptors; SRA: Sequence read archive; SSR: Simple sequence repeats; TBD: TBK1/IKKi-binding domain; TBK: TANK binding kinase; TEP: Thioester-containing proteins; TGICL: TIGR gene indices clustering tool; TLR: Toll-like receptors; TNF: Tumor-necrosis factor; TRAF: Tumor necrosis factor receptor-associated factor UTR: Untranslated regions; WEGO: Web gene ontology annotation plot

\section{Acknowledgements}

Not Applicable

\section{Availability of data and materials}

The datasets generated and analysed during the current study are available in the Sequence Read Archive (SRA) database at NCBI under the accession number SRR5936593, [https://www.ncbi.nlm.nih.gov/sra/?term=SRR5936593].

\section{Funding}

The design, analysis, and interpretation of data in this work was supported by Soonchunhyang University Research Fund, the grant entitled "Genetic Diversity Studies of Useful Wildlife Resources" funded by the National Institute of Biological Resources (NIBR201703203) and the Basic Science Research Program through the National Research Foundation of Korea (NRF) funded by the Ministry of Science, ICT \& Future Planning (NRF-2017-R1D1A3B06034971).

\section{Authors contributions}

BBP, JMC, HJH, MKS, ND, and SB conducted the experiments. JEP, HRM, and HCC collected specimens and conducted data management. BBP, JMC, ND, SYP, and SWK contributed to data analysis, data interpretation, and manuscript preparation. YHJ, WJK, YSH, BBP, and YSL contributed to scholastic intellectual content and data review. YSH, HSP, JSL, and YSL contributed to sequencing study and data management. YSH and YSL conceived the study. All authors have read and approved the manuscript.

\section{Ethics approval and consent to participate}

No permission was required for the collection of slugs in this study. Further, this study was approved by Soonchunhyang University, South Korea. This study was conducted in accordance to the ethical guidelines for use of experimental animals in biomedical research.

\section{Consent for publication}

Not applicable

\section{Competing interests}

The authors declare that they have no competing interests.

\section{Publisher's Note}

Springer Nature remains neutral with regard to jurisdictional claims in published maps and institutional affiliations.

\section{Author details}

${ }^{1}$ Department of Life Science and Biotechnology, College of Natural Sciences, Soonchunhyang University, 22 Soonchunhyangro, Shinchang-myeon, Asan, Chungchungnam-do 31538, South Korea. ${ }^{2}$ School of Biotech Sciences, Trident Academy of Creative Technology (TACT), F2-B, Chandaka Industrial Estate, Chandrasekharpur, Bhubaneswar, Odisha 751024, India. ${ }^{3}$ Biological Resource Center, Korea Research Institute of Bioscience and Biotechnology (KRIBB), 181, Ipsin-gil, Jungeup-si, Jeollabuk-do 56212, South Korea. ${ }^{4}$ Nakdonggang National Institute of Biological Resources, Biodiversity Conservation and Change Research Division, 137, Donam-2-gil, Sangju-si, Gyeongsangbuk-do 37242, South Korea. ${ }^{5}$ College of Agriculture and Life Science, Chonnam National University, 77 Yongbong-ro, Buk-gu, Gwangju 61186, South Korea. ${ }^{6}$ Research Institute, GnC BIO Co., LTD, 621-6 Banseok-dong, Yuseong-gu, Daejeon 34069, Republic of Korea. ${ }^{7}$ Institute of Basic Science, Soonchunhyang University, 22 Soonchunhyangro, Shinchang-myeon, Asan, Chungchungnam-do 31538, South Korea.

Received: 7 July 2018 Accepted: 11 February 2019

Published online: 26 February 2019

\section{References}

1. Collinge WE. Description of some new species of slug collected by Mr. H Fruhstofer J Malacol. 1901;8:118-21.

2. Noseworthy RG, Lim NR, Choi KS. A catalogue of the mollusks of Jeju Island, South Korea. Kor J Malacol. 2007:23:65-104.

3. Yuasa HJ, Furuta E, Nakamura A, Takagi T. Cloning and sequencing of three C-type lectins from body surface mucus of the land slug, Incilaria fruhstorferi. Comp Biochem Physiol B, Comp Biochem. 1998;119:479-84.

4. Heylands A, Vue Z, Voolstra CR, Medina M, Moroz LL. Developmental transcriptome of Aplysia californica. J Exp Zool B Mol Dev Evol 2011;0: 113-134

5. Gomez-Chiarri M, Warren WC, Guo X, Proestou D. Developing tools for the study of molluscan immunity: the sequencing of the genome of the eastern oyster, Crassostrea virginica. Fish shellfish Immunol. 2015;46: 2-4.6. Raghavan N, Knight M. The snail (Biomphalaria glabrata) genome project. Trends Parasitol. 2006;22:148-51.

6. Raghavan N, Knight M. The snail (Biomphalaria glabrata) genome project. Trends Parasitol. 2006;22:148-51.

7. Schell T, Feldmeyer B, Schmidt H, Greshake B, Tills O, Truebano M, Rundle SD, Paule J, Ebersberger I, Pfenninger M. An annotated draft genome for Radix auricularia (Gastropoda, Mollusca). Genome Biol Evol. 2017;9. 
8. Mun S, Kim Y-J, Markkandan K, Shin W, Oh S, Woo J, Yoo J, An H, Han K. The whole -genome and transcriptome of the Manila clam (Ruditapes philippinarum). Genome Biol Evol. 2017;9:1487-98.

9. Doucet-Beaupre H, Breton S, Chapman EG, Blier PU, Bogan AE, Stewart DT, Hoeh WR. Mitochondrial phylogenomics of the Bivalvia (Mollusca): searching for the origin and mitogenomic correlates of doubly uniparental inheritance of mtDNA. BMC Evol Biol. 2010;10:50.

10. Allcock AL, Cooke IR, Strugnell JM. What can the mitochondrial genome reveal about higher-level phylogeny of the molluscan class Cephalopoda? Zool J Linnean Soc. 2011;161:573-86.

11. Kang SW, Patnaik BB, Hwang H-J, Park SY, Chung JM, Song DK, Patnaik HH, Lee JB, Kim C, Kim S, Park HS, Park S-H, Park Y-S, Han YS, Lee JS, Lee YS. Sequencing and de novo assembly of visceral mass transcriptome of the critically endangered land snail Satsuma myomphala: annotation and SSR discovery. Comp Biochem Physiol Part D: Genomics and Proteomics. 2017a; 21:77-812.

12. Patnaik BB, Wang TH, Kang SW, Hwang H-J, Park SY, Park EB, Chung JM, Song DK, Kim C, Kim S, Lee JS, Han YS, Park HS, Lee YS. Sequencing, De novo assembly, and annotation of the transcriptome of the endangered freshwater pearl bivalve, Cristaria plicata, provides novel insights into functional genes and marker discovery. PLoS One. 2016;11:e0148622

13. Baten A, Ngangbam AK, Waters DL, Benkendorff K. Transcriptome of the Australian Mollusc Dicathais orbita provides insights into the biosynthesis of indoles and choline esters. Mar Drugs. 2016;14.

14. Ertl NG, O 'Connor WA, Papanicolaou a, Wiegand AN, Elizur a. Transcriptome analysis of the Sydney rock oyster, Saccostrea glomerata: insights into molluscan immunity. PLoS One 2016;11: E0156649.

15. Zhao J-S, Wang A-Y, Zhao H-B, Chen $Y-H$. Transcriptome sequencing and differential gene expression analysis of the schistosome-transmitting snail Oncomelania hupensis inhabiting hilly and marshland regions. Sci Rep. 2017; 7:15809.

16. Parmakelis A, Kotsakiozi P, Kontos CK, Adamopoulos PG, Scorilas A. The transcriptome of a 'sleeping' invader: de novo assembly and annotation of the transcriptome of aestivating Cornu aspersum. BMC Genomics. 2017;18:491.

17. Sun X, Li D, Liu Z, Zhou L, Wu B, Yang A. De novo assembly of pen shell (Atrina pectinata) transcriptome and screening of its genic microsatellites. J Ocean Univ China. 2017;16:882-8.

18. Kang SW, Patnaik BB, Hwang H-J, Park SY, Wang TH, Park EB, Chung JM, Song DK, Patnaik HH, Lee JB, Kim C, Kim S, Park HS, Lee JS, Han YS, Lee YS. De novo transcriptome generation and annotation for two Korean endemic land snails, Aegista chejuensis and Aegista quelpartensis, using Illumina paired-end sequencing technology. Int J Mol Sci. 2016a;17:379.

19. Kang SW, Patnaik BB, Park SY, Hwang H-J, Chung JM, Sang MK, Min HR, Park JE, Seong J, Jo YH, Noh MY, Lee JD, Jung KY, Park HS, Han YS, Lee JS. Lee YS. Transcriptome analysis of the threatened snail Ellobium chinense reveals candidate genes for adaptation and identifies SSRs for conservation genetics. 2017b. https://doi.org/10.1007/s13258-017-0620-x.

20. Kang SW, Park SY, Patnaik BB, Hwang H-J, Kim C, Kim S, Lee JS, Han YS, Lee YS. Construction of PANM database (protostome DB) for rapid annotation of NGS data in mollusks. Korean J Malacol. 2015;31:243-7.

21. Cho A, Seok SH. Ethical guidelines for use of experimental animals in biomedical research. J Bacteriol Virol. 2013;43:18-26.

22. Martin M. Cutadapt removes adapter sequences from high-throughput sequencing reads. EMBnet J. 2011;17:10-2.

23. Li W, Godzik A. Cd-hit: a fast program for clustering and comparing large sets of protein or nucleotide sequences. Bioinformatics. 2006;22:1658-9.

24. Waterhouse RM, Seppey M, Simao FA, Manni M, loannidis P, Klioutchnikov G, Kriventseva EV, Zobnov EM. BUSCO applications from quality assessments to gene prediction and phylogenomics. Mol Biol Evol. 2017;35:543-8.

25. Zdobnov EM, Tegenfeldt F, Kuznetsov D, Waterhouse RM, Simao FA, loannidis $P$, Seppey M, Loetscher A, Kriventseva EV. OrthoDB v9.1: cataloguing evolutionary and functional annotations for animal, fungal, plant, archaeal, bacterial and viral orthologs. Nucleic Acids Res. 2016;45:D744-9.

26. Kang SW, Park SY, Patnaik BB, Hwang HJ, Chung JM, Song DK, Park SY, Lee JS, Han YS, Park HS, Lee YS. The Protostome Database (PANM-DB): Version 2.0 release with updated sequences. Korean J Malacol. 2016b;32: 185-188.

27. Ye J, Zhang Y, Cui H, Liu J, Wu Y, Cheng Y, Xu H, Huang X, Li S, Zhou AZX, Bolund L, Chen Q, Wang J, Yang H, Fang L, Shi C. WEGO 2.0: a web tool for analysing and plotting GO annotations, 2018 update. Nucleic Acids Res. Gky400, https://doi.org/10.1093/nar/gky400.
28. Solovyev V, Kosarev P, Seledsov I, Vorobyev D. Automatic annotation of eukaryotic genes, pseudogenes and promoters. Genome Biol. 2006;7:S10.

29. Min XJ, Butler G, Storms R, Tsang A. OrfPredictor: predicting protein-coding regions in EST-derived sequences. Nucleic Acids Res. 2005;33:W677-80.

30. Larkin MA, Blackshields G, Brown NP, Chenna R, McGettigan PA, McWilliam H, Valentin F, Wallace IM, Wilm A, Lopez R, Thompson JD, Gibson TJ, Higgins DG. Clustal W and Clustal X version 2.0. Bioinformatics. 2007;23: 2947-8.

31. Nicholas KB, Nicholas HB, Deerfield DW. Analysis and visualization of genetic variation. GeneDoc. 1997:4 ISSN1023-4144.

32. Xiao M, Zhang Y, Chen X, Lee E-J, Barber CJS, Chakrabarty B, Desgagne-Penix I, Haslam TM, Kim Y-B, Liu E, MacNevin G, Masada-Atsumi S, Reed DW, Stout JM, Zerbe P, Zhang Y, Bohlmann J, Covello PS, De Luca V, Page JE, Ro D-K, Martin VJJ, Facchini PJ, Sensen CW. Transcriptome analysis based on next-generation sequencing of non-model plants producing specialized metabolites of biotechnological interest. J Biotechnol. 2013;166:122-34.

33. Hwang HJ, Patnaik BB, Kang SW, Park SY, Wang TH, Park EB, Chung JM, Song DK, Patnaik HH, Kim C, Kim S, Lee JB, Jeong HC, Park HS, Han YS, Lee YS. RNA sequencing, de novo assembly and functional annotation of a nymphalid butterfly, Fabriciana nerippe Felder, 1862. Entomol Res. 2016. https://doi.org/10.1111/1748-5967.12164.

34. Deng Y, Lei Q, Tian Q, Xie S, Du X, Li J, Wang L, Xiong Y. De novo assembly, gene annotation, and simple sequence repeat marker development using Illumina paired-end transcriptome sequences in the pearl oyster Pinctada maxima. Biochem Mol Biol. 2014;78:1685-92.

35. Huerlimann R, Wade NM, Gordon L, Montenagro JD, Goodall J, McWilliam S, Tinning M, Siemering K, Giardina E, Donovan D, Sellars MJ, Cowley JA, Condon K, Coman GJ, Khatkar MS Raadsma HW, Maes GE, Zenger KR, Jerry DR. De novo assembly, characterization, functional annotation and expression patterns of the black tiger shrimp (Penaeus monodon) transcriptome. 2018;8: 13553.

36. Hwang HJ, Patnaik BB, Kang SW, Park SY, Chung JM, Sang MK, Park JE, Min HR, Seong J, Jo YH, Noh MY, Lee JD, Jung KY, Park HS, Jeong HC, Lee YS. RNA sequencing, De novo assembly, functional annotation and SSR analysis of the endangered diving beetle, Cybister chinensis (= Cybister japonicus) using the Illumina platform. Entomol Res. 2018:60-72.

37. Brayer KJ, Segal DJ. Keep your fingers off my DNA: protein-protein interactions mediated by $\mathrm{C} 2 \mathrm{H} 2$ zinc finger domains. Cell Biochem Biophys. 2008;50:111-31.

38. Potapov V, Sobolev V, Edelman M, Kister A, Gelfand I. Protein-protein recognition: juxtaposition of domain and interfaces cores in immunoglobulins and other sandwich-like proteins. J Mol Biol. 2004;342:665-79.

39. Terada D, Kawai F, Noguchi H, Unzai S, Hasan I, Fujii Y, Park S-Y, Ozeki Y, Tame JRH. Crystal structure of MytiLec, a galactose-binding lectin from the mussel Mytilus galloprovincialis with cytotoxicity against certain cancer cell types. Sci Rep. 2016;6:28344.

40. Tasumi S, Vasta GR. A galectin of unique domain organization from hemocytes of the eastern oyster (Crassostrea virginica) is a receptor for the protistan parasite Perkinsus marinus. J Immunol. 2007;179:3086-98.

41. Kim JY, Kim YM, Cho SK, Choi KS, Cho M. Noble tandem-repeat galectin of Manila clam Ruditapes philippinarum is induced upon infection with the protozoan parasite Perkinsus olseni. Dev Comp Immunol. 2008;32: 1131-41.

42. Galperin MY, Kolker E. New metrics for comparative genomics. Curr Opin Biotechnol. 2006;17:440-7.

43. Chen $H$, Zha J, Liang $X, B u$ J, Wang M, Wang Z. Sequencing and de novo assembly of the Asian clam (Corbicula fluminea) transcriptome using the Illumina GAllx method. PLoS One. 2013:8:e795616.

44. Tong Y, Zhang Y, Huang J, Xiao S, Zhang Y, Li J, Chen J, Yu Z. Transcriptomics analysis of Crassostrea hongkongensis for the discovery of reproduction-related genes. PLoS One. 2015;10:e0134280.

45. Kanehisa M, Goto S, Kawashima S, Okuno Y, Hattori M. The KEGG resource for deciphering the genome. Nucleic Acids Res. 2004;32:D277-80.

46. Jurka J, Kapitonov W, Pavlicek A, Klonowski P, Kohany O, Walichiewicz J. Repbase Update, a database of eukaryotic repetitive elements. Cytogenet Genome Res. 2005;110: 462-467.

47. Casacuberta E, Gonzalez J. The impact of transposable elements in environmental adaptation. Mol Ecol. 2013;22:1503-17.

48. Stapley J, Santure AW, Dennis SR. Transposable elements as agents of rapid adaptation may explain the genetic paradox of invasive species. Mol Ecol. $2015 ; 24: 2241-52$. 
49. Li YC, Korol AB, Fahima T, Beiles A, Nevo E. Microsatellites: genomic evolution, putative functions and mutational mechanisms: a review. Mol Ecol. 2002;11:2453-65.

50. Lopez-Uribe M, Santiago C, Bogdanowicz S, Danforth B. Discovery and characterization of microsatellites for the solitary bee Colletes inaequalis using sanger and 454 pyrosequencing. Apidologie. 2013;44:163-72.

51. Vidotto M, Grapputo A, Boscari E, Barbisan F, Coppe A, Grandi G, Kumar A, Congiu L. Transcriptome sequencing and de novo annotation of the critically endangered Adriatic sturgeon. BMC Genomics. 2013;14:407.

52. Park SY, Patnaik BB, Kang SW, Hwang H-J, Chung JM, Song DK, Sang MK, Patnaik HH, Lee JB, Noh MY, Kim C, Kim S, Park HS, Lee JS, Han YS, Lee YS. Transcriptomic analysis of the endangered Neritid species Clithon retropictus: De novo assembly, functional annotation, and marker discovery. Genes. 2016;7:35.

53. Moreira R, Pereiro P, Balseiro P, Milan M, Pauletto M, Bargelloni L, Novoa B, Figueras A. Revealing Mytilus galloprovincialis transcriptome profiles during ontogeny. Dev Comp Immunol. 2018;84:292-306.

54. Song H, Yu Z-L, Sun L-N, Xue D-X, Zhang T, Wang H-Y. Transcriptomic analysis of differentially expressed genes during larval development of Rapana venosa by digital gene expression profiling. G3 (Bethesda);6: 2181-2193.

55. Janeway CA, Medzhitov R. Innate immune recognition. Annu Rev Immunol. 2002;20:197-216

56. Song X, Dai D, He X, Zhu S, Yao Y, Gao H, Wang J, Qu F, Qiu J, Wang H, Li X, Shen N, Qian Y. Growth factor FGF2 cooperates with interleukin 17 to repair intestinal epithelial damage. Immunity. 2016;43:488-501.

57. Zhang G, Ghosh S. Negative regulation of toll-like receptor-mediated signalling by Tollip. J Biol Chem. 2002;277:7059-65.

58. Zhang R, Li R, Wang J, Wang S, Zhang M, Hu X, Zhang L, Wang S, Wang R, Bao Z. Identification, characterization and expression profiling of the Tollip gene in yesso scallop (Patinopecten yessoensis). Genes Genet Syst. 2015;90: 99-108.

59. Wei J, Guo M, Gao P, Ji H, Li P, Yan Y, Qin Q. Isolation and characterization of tumor necrosis factor receptor-associated factor 6 (TRAF6) from grouper, Epinephelus tauvina. Fish Shellfish Immunol. 2014;39:61-8.

60. Wang P-H, Gu Z-H, Wan D-H, Zhu W-B, Qiu W, Chen Y-G, Weng S-P, Yu X-Q, He J-G. Litopenaeus vannamei toll-interacting protein (LvTollip) is a potential negative regulator of the shrimp toll pathway involved in the regulation of the shrimp antimicrobial peptide gene penaeidin-4 (PEN4). Dev Comp Immunol. 2013;40:266-77.

61. Lv Z, Li C, Zhang P, Wang Z, Zhang W, Jin C-H. miR-200 modulates coelomocytes antibacterial activities and LPS priming via targeting Tollip in Apostichopus japonicus. Fish and Shellfish Immunol. 2015;45:431-6.

62. Ankem G, Mitra S, Sun F, Moreno AC, Chutvirasakul B, Azurmendi HF, Li L, Capelluto DG. The C2 domain of Tollip, a toll-like receptor signalling receptor, exhibits broad preference to phosphoinositides. Biochem J. 2011 435:597-608.

63. Katoh Y, Shiba Y, Mitsuhashi H, Yanagida Y, Takatsu H, Nakayama K. Tollip and Tom1 form a complex and recruit ubiquitin-conjugated proteins onto early endosomes. J Biol Chem. 2004;279:24435-43.

64. Mitra S, Traughber CA, Brannon MK, Gomez S, Capelluto DG. Ubiquitin interacts with the Tollip C2 and CUE domains and inhibits binding of Tollip to phosphoinositides. J Biol Chem. 2013;288:25780-91.

65. Luiz DP, Santos Junior CD, Bonetti AM, Brandeburgo MAM. Tollip or not Tollip: what are the evolving questions behind it? PLoS One. 2014;9: e97219.

66. Yang JL, Wang W, Wei XM, Qiu LM, Wang LL, Zhang H, Song LS. Peptidoglycan recognition protein of Chlamys farreri (CFPGRP-S1) mediates immune defenses against bacterial infection. Dev Comp Immunol. 2010;34:1300-7.

67. Dziarski R, Gupta D. The peptidoglycan recognition proteins (PGRPs). Genome Biol. 2006;7:232

68. Premchandra HK, Elvitigala DA, Whang I, Lee J. Identification of a novel molluscan short-type peptidoglycan recognition protein in disk abalone (Haliotis discus discus) involved in host antibacterial defense. Fish Shellfish Immunol. 2014;39:99-107.

69. Wei X, Yang J, Yang D, Xu J, Liu X, Yang J, Fang J, Qiao H. A sigma class glutathione-s-transferase from Solen grandis that responded to microorganism glycan and organic contaminants. Fish Shellfish Immunol. 2012;32:1198-204

70. Ni D, Song L, Wu L, Chang Y, Yu Y, Qiu L, Wang L. Molecular cloning and mRNA expression of peptidoglycan recognition protein (PGRP) gene in bay scallop (Argopecten irradians, Lamarck 1819). Dev Comp Immunol. 2007;31:548-58.
71. Yang J, Wang W, Wei X, Qiu L, Wang L, Zhang H, Song L. Peptidoglycan recognition protein of Chlamys farreri (CFPGRP-S1) mediates immune defenses against bacterial infection. Dev Comp Immunol. 2010;34:1300-7.

72. Zhang L, Li L, Guo X, Litman GW, Dishaw LJ, Zhang G. Massive expansion and functional divergence of innate immune genes in a protostome. Sci Rep. 5: 8693.

73. Detree C, Lallier FH, Tanguy A, Mary J. Identification and gene expression of multiple peptidoglycan recognition proteins (PGRPs) in the deep-sea musse Bathymodiolus azoricus, involvement in symbiosis. Comp Biochem Physiol B Biochem Mol Biol. 2017;207:1-8.

74. Guan R, Roychowdhury A, Ember B, Kumar S, Boons G-J, Mariuzza RA. Structural basis for peptidoglycan binding by peptidoglycan recognition proteins. Proc Natl Acad Sci U S A. 2004;101:17168-73.

75. Liu L, Yang J, Qiu L, Wang L, Zhang H, Wang M, Vinu SS, Song L. A novel scavenger receptor-cysteine rich (SRCR) domain containing scavenger receptor identified from mollusk mediated PAMP recognition and binding. Dev Comp Immunol. 2011;35:227-39.

76. Guo X, Ford SE. Infectious diseases of marine molluscs and host responses as revealed by genomic tools. Philos Trans R Soc Lond Ser B Biol Sci. 2016 371:20150206

77. Wang W, Song X, Wang L, Song L. Pathogen-derived carbohydrate recognition in molluscs immune defense. Int J Mol Sci. 2018;19:721.

78. Toubiana M, Gerdol M, Rosani U, Pallavivini A, Venier P, Roch P. Toll-like receptors and MyD88 adaptors in Mytilus: complete cds and gene expression levels. Dev Comp Immunol. 2013;40:158-66.

79. Wang $M$, Wang $L$. Jia Z, Yi Q, Song L. The various components implied the diversified toll-like receptor (TLR) signaling pathways in mollusk Chlamys farreri. Fish Sellfish Immunol 2018;74: 205-212.

80. Ren $Y$, Pan H, Pan B, Bu W. Identification and functional characterization of three TLR signaling pathway genes in Cyclina sinensis. Fish Shellfish Immunol. 2016;50:150-9.

81. Akira S, Takeda K. Toll-like receptor signaling. Nat Rev Immunol. 2004;4:499511.988.

82. Wang S, Hou R, Bao Z, Du H, He Y, Su H, Zhang Y, Fu X, Jiao W, Li Y, Zhang L, Wang S, Hu X. Transcriptome sequencing of Zhikong scallop (Chlamys farreri) and comparative transcriptomic analysis with yesso scallop (Patinopecten yessoensis). PLoS One. 2013;8:e63927.

83. Brokordt KB, Gonzalez RC, Farias WJ, Winkler FM. Potential response to selection of HSP70 as a component of innate immunity in the abalone Haliotes rufescens. PLoS One. 2015;10:e0141959.

84. Liang HY, Wang ZX, Lei RL, Huang YW, Deng QH, Jiao WY, Du XD. Molecular cloning and expression analysis of a pearl oyster (Pinctada martensii) heat shock protein 90 (HSP90). Genet Mol Res. 2015;14:18778-91.

85. Ray M, Bhunia NS, Bhunia AS, Ray S. Expression analysis of interferon gamma, tumor necrosis factor, alpha and inducible nitric oxide synthase in the hemocyte morphotypes of two commercially Indian molluscs. Aquaculture Rep. 2016;4:30-5.

86. Meng X, Tian X, Nie G, Wang J, Liu M, Jiang K, Wang B, Guo Q, Huang J, Wang $L$. The transcriptome response to copper exposure in the digestive gland of Japanese scallops (Mizuhopecten yessoensis). Fish Shellfish Immunol. 2015;46:161-7.

87. Birben E, Sahiner UM, Sackesen C, Erzurum S, Kalayci O. Oxidative and antioxidant defense. World Allergy Organ J. 2012;5:9-19.

88. Hu X, Hu X, Hu B, Wen C, Xie Y, Wu D, Tao Z, Li A, Gao Q. Molecular cloning and characterization of cathepsin L from freshwater mussel, Cristaria plicata Fish Shellfish Immunol 2014; 40: 446-454.

89. Jenny MJ, Ringwood AH, Lacy ER, Lewitus AJ, Kempton JW, Gross PS, Warr GW, Chapman RW. Indicators of stress response identified by expressed sequence tag analysis of hemocytes and embryos from the American oyster, Crassostrea virginica Mar Biotechnol 2002; 4: 81-93.

90. Godahewa Gl, Perera NCN, Lee S, Lee J. A cysteine protease (cathepsin Z) from disk abalone, Haliotis discus: genomic characterization and transcriptional profiling during bacterial infections. Gene. 2017;627:500-7.

91. Sang MK, Hwang H, Kang SW, Park S, Park So, Chung JN, Park JE, Min HR, Lee JS, Han YS, Park HS, Won R, Lee YS. Molecular phylogenetic study of Incilaria fruhstorferi based on Metallothionein gene. Korean J Malacol. 2017; 33: 259-265.

92. Ashe AC, Berry MD. Apoptotic signalling cascades. Prog Neuro-Psychopharmacol Biol Psychiatry. 2003;27:199-214.

93. Teaniniuraitemoana V, Huvet A, Levy P, Klopp C, Lhuillier E, Gaertner-Mazouni N, Gueguen Y, Le Moullac G. Gonad transcriptome analysis of pearl oyster Pinctada 
margaritifera: identification of potential sex-differentiation and sex-determining genes. BMC Genomics. 2014;15:491.

94. Chen H, Xiao G, Chai X, Lin X, Fang J, Teng S. Transcriptome analysis of sex-related genes in the blood clam Tegillarca granosa. PLoS One. 2017;12:e01845.

95. Kim MA, Rhee JS, Kim TH, Lee JS, Choi AY, Choi BS, Choi IY, Sohn YC. Alternative splicing profile and sex-preferential gene expression in the female and male Pacific abalone Haliotis discus hannai. Genes. 2017;8(3):99

96. Doniach T, Hodgkin J. A sex-determining gene, fem-1, required for both male and hermaphrodite development in Caenorhabditis elegans. Dev Biol. 1984;106:223-35.

97. Jiang Y, Ding Q, Xie X, Libby RT, Lefebvre V, Gan L. Transcription factors SOX4 and SOX11 function redundantly to regulate the development of mouse retinal ganglion cells. J Biol Chem. 2013;288:18429-38.

98. Ghiselli F, Milani L, Chang PL, Hedgecock D, Davis JP, Nuzhdin SV, Passamonti M. De novo assembly of the Manila clam Ruditapes philippinarum transcriptome provides new insights into expression bias, mitochondrial doubly uniparental inheritance and sex determination. Mol Biol Evol. 2012;29:771-86.

99. Li H, Zhang Z, Bi Y, Yang D, Zhang L, Liu J. Expression characteristics of $\beta$ catenin in scallop Chlamys farreri gonads and its role as a potential upstream gene of Dax1 through canonical Wnt signalling pathway regulating the spermatogenesis. PLoS One. 2014;9:e115917.

100. Santerre C, Sourdaine P, Adeline B, Martinez AS. Cg-SoxE and cg-B-catenin, two new potential actors of the sex-determining pathway in a hermaphrodite lophotrochozoan, the Pacific oyster Crassostrea gigas. Comp Biochem Physiol A Mol Integr Physiol. 2014;167:68-76.

101. Llera-Herrera R, Garcia-Gasca A, Abreu-Goodger C, Huvet A, Ibarra AM. Identification of male gametogenesis expressed genes from the scallop Nodipecten subnodosus by suppressive subtraction hybridization and pyrosequencing. PLoS One. 2013;8:e73176.

102. Jung H, Lyons RE, Hurwood DA, Mather PB. Genes and growth performance in crustacean species: a review of relevant genomic studies in crustaceans and other taxa. Rev Aquaculture. 2013;5:77-110.

103. Lv J, Liu P, Gao B, Wang Y, Wang Z, Chen P, Li J. Transcriptome analysis of the Portunus trituberculatus: De novo assembly, growth-related gene identification and marker discovery. PLoS One. 2014;9:e94055.

104. Wang Z, Shang P, Li Q, Wang L, Chamba Y, Zhang B, Zhang H, Wu C. iTRAQ-based proteomic analysis reveals key proteins affecting muscle growth and lipid deposition in pigs. Sci Rep. 2017;7:46717.

105. van der Merwe M, Auzoux-Bordenave S, Niesler C, Roodt-Wilding R. Investigating the establishment of primary cell culture from different abalone (Haliotis midae) tissues. Cytotechnol. 2010;62:265-77.

106. De Santis C, Jerry DR. Candidate growth genes in finfish - where should we be looking? Aquaculture. 2007;272:22-38.

107. Monnier Z, Bride M. In vitro effects of methionine-enkephalin, somatostatin and insulin on cultured gonadal cells of the snail Helix aspera. Experientia. 1995:51:824-30.

108. Smit AB, Spijker S, Van Minnen J, Burke JF, De Winter F, Van Elk R, Geraerts WP. Expression and characterization of molluscan insulin-related peptide VII from the mollusc Lymnaea stagnalis. Neurosci. 1996;70:589-96.

109. Zhang M, Wang Y, Li Y, Li W, Li R, Xie X, Wang S, Hu X, Zhang L, Bao Z. Identification and characterization of neuropeptides by transcriptome and proteome analyses in a bivalve mollusc Patinopecten yessoensis. Front Genet. https://doi.org/10.3389/fgene.2018.00197.

110. Floyd PD, Li L, Rubakhin SS, Sweedler JV, Horn CC, Kupfermann I, Alexeeva V. Ellis TA, Dembrow NC, Weiss KR, Vilim FS. Insulin prohormone processing, distribution and relation to metabolism in Aplysia californica. J Neurosci. 1999;19:7732-41

111. Ahn SJ, Martin R, Rao S, Choi MY. Molecular approach to control slugs: transcriptome of the gray garden slug. Proc Pacific Northwest Insect Management Conference. 2017.

112. DesGroseillers L, Auclair D, Wickham L, Maalouf M. A novel actin cDNA expressed in the neurons of Aplysia californica. Biochim Biophys Acta. 1994; 1217:322-4.
113. Sin FYT, Bryant MJ, Johnstone A. Molecular evolution and phylogeny of actin genes in Haliotis species (Mollusca: Gastropoda). Zool Stud. 2007;46: 734-45.

114. Huang J, You W, Luo X, Ke C. iTRAQ-based identification of proteins related to muscle growth in the Pacific abalone, Haliotis discus hannai Int J Mol Sci 2017;18: 2237

115. Ma H, Mai K, Liufu Z, Wei X. Cloning and characterization of an actin gene of Chlamys farreri and the phylogenetic analysis of mollusk actins. Chinese J Oceanology Limnology. 2007;25:304-9.

116. Ivanov M, Todorvska E, Radkova M, Georgiev O, Dolashki A, Dolashka P. Molecular cloning, characterization and phylogenetic analysis of actin gene from the marine mollusk Rapana venosa (class Gastropoda). Int I Curr Microbiol App Sci. 2015;4:687-700.

\section{Ready to submit your research? Choose BMC and benefit from:}

- fast, convenient online submission

- thorough peer review by experienced researchers in your field

- rapid publication on acceptance

- support for research data, including large and complex data types

- gold Open Access which fosters wider collaboration and increased citations

- maximum visibility for your research: over $100 \mathrm{M}$ website views per year

At BMC, research is always in progress.

Learn more biomedcentral.com/submissions 